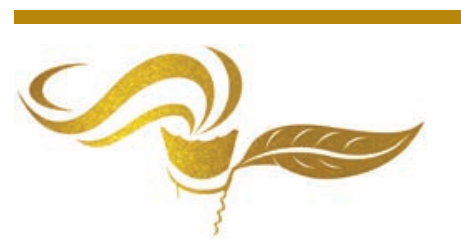

\title{
Electrome \& Cognition Modes in Plants: A Transdisciplinary Approach to the Eco-Sensitiveness of the World
}

\section{Marc-Williams Debono}

PSA Research Group (Palaiseau, France), email: psa-rg@plasticites-sciences-arts.org

Received November 1, 2020; Revised November 30, 2020; Accepted December 1, 2020

Available online December 2, 2020 at www.atlas-journal.org, doi: 10.22545/2020/00143

\begin{abstract}
$\mathrm{R}$ ecent studies on plant-environment and plant-human relationships reveal the need to reassess the scales of perception, sensitiveness and cognition of living systems. The complexity of plant's emerging behaviors in interaction with the environment is supported by the signature of the electrome and the plant sensorium, a strong argument to establish the singularity of the living and weights its consequences in evolutionary, ecological or socioeconomic terms. This paper highlights the cognitive value of access to the experience of plants and its fundamentally mesological or ecoplastic nature, that is to say in direct connection with a singular milieu. This dynamic coupling makes it possible to explain the co-construction of an intelligible and sensible world without the use of a brain, principle that reframes the concept of intelligent behavior while revealing both the frontiers in cognition and the strong transdisciplinary challenges of an acute awareness of the man's fragility as of the planetary ecosystem at the era of the Antropocene.
\end{abstract}

Keywords: Plant behavior, environment, electrome signature, sensitiveness, mesological plasticity, cognitive processes, plastic interfaces, transdisciplinarity.

\section{Introduction}

The electrome, defined in analogy to the biome or genome, as the electrical dimension of plant life (De Loof 2016, Toledo et al., 2019) [1,2], represents, among the various cell signaling systems, one of the major means of treatment information in plants, and by extension for all living systems. At a plant cell level, it is characterized in particular by the presence of proton pumps and the permanent opening / closing of ion channels anchored in the plasma membrane by the cytoskeleton at the origin of action potentials (PA), by plasmodesms for the propagation of signals at short distance (cell to cell communication) and by the vascular and hydraulic systems at the xylem or phloem level depending on the direction of circulation for the transport of material or nutrients like sugar, hormone or chemical mediators, liquids... (Hedrich et al. 2016, Choi et al. 2017) [3, 4]. These electrochemical gradients generate potential differences (PDs) that can be collected by intracellular recordings (membrane potentials and action potentials modeled by the Hodgkin-Huxley equation applying to excitable cells) and extracellular ones (collected with non-polarizable $\mathrm{Ag} / \mathrm{AgCl}$ electrodes placed in situ on the surface of a leaf or in the tissues of a stem or root). The latter 
Marc-Williams Debono

Electrome \& Cognition Modes in Plants: A Transdisciplinary Approach to the Eco-Sensitiveness

of the World

allows, once stabilized in situ, to observe the mathematical derivative or the algebraic summation of the signals underlying all of the tissue PDs by so-called electrophytographic techniques (EPG). Their permanent experimental presence has been demonstrated and characterized in the form of "surface potentials" or spontaneous electrical variations of low amplitude $(25-500 \mu \mathrm{V})$ interspersed with spikes at the level of the whole plant in Kalanchoë D. by Debono et al. (1992, 2013) [5, 6].

The presence of these electrophytograms or EPGs has recently been validated by several independent international teams, including those of Masi et al. [7] (spatiotemporal course of spontaneous EPGs and synchronization of long-distance spikes recorded by MEA 60 channels on roots of maize, 2009); of Cabral et al. (modeling of complex oscillatory bioelectric signals, 2011) [8] and Saraiva et al. and Souza et al., (2017) (recording of spontaneous EPGs and spikelets induced after osmotic shocks by high resolution spectral analysis on shoots of soy) [9,10] with whom we are now collaborating (Toledo et al. 2019, Debono and Souza, 2019) [2, 11]. In all these models and with different technologies, long-term EPG recordings with the same signal-to-noise ratio, complex oscillatory behaviors and similar reactivity to stimuli were found. EPG-type electrophysiological activities are then added to the directory of all classic PA-type emissions, systemic potentials or bioelectric fields and generate a specific signature of the electrome. Its biodynamics can turn out to be totally different before and after a stimulus, spreads over a long distance or even can be synchronized in order to cover the sensory information flows that constantly assails plants.

\section{Signature of the Electrome: Self-organized Complex (SOC) and Recording of Electrophytograms (EPGs)}

The initial question that we asked about the physiological role of these biosensors and their non-linear dynamic impact on active plant perception systems [5] thus begins to have solid experimental answers indicating: 1/ that the chemical communication through volatile substances etc. is not the only one brought into play and 2/ that EPGs are an integral part of the plant's electrome, considered as a self-organized complex with "multicolored" noise summing up all of the ionic, systemic and electrical directories repertoires of plant tissues $[4,10]$. To the detailed classification of the different types of plant electrophysiological activities (action, variation, systemic and local potentials, ROS, Ca2+ waves..) established by Fromm \& Lautner (2007) [12], we must therefore now add the EPGs. They are analogous in terms of amplitude to EEGs conventionally recorded in animals (mathematical derivative representing the algebraic sum of biomolecular signals associated with polarization-depolarization processes), but present neither the same temporality, nor the same degree of synchronization or correlation.

More specifically, the spontaneous EPGs that we collected at tissue level are interspersed with sharp oscillations or isolated spikes which can be organized as discharges lasting several seconds or minutes after a stimulation, whether natural or evoked [5, 6]. Souza et al. (2017) recently showed that the EPGs follow a power law which represents the mathematical relation between two quantities defined by the constants a (proportionality) and k (exponent) and are used at the level of large systems presenting invariant scales. Under certain conditions, they can push them towards a self-organized critical state (SOC or self-organized criticality) representative of nonlinear dynamic systems [9, 10]. The working hypothesis that we support regarding these SOCs is that a constant EPG monitoring of plants would allow to discriminate and manage environmental stimuli in real time (water supply during drought, new climatological conditions, interaction with neighboring species, osmotic shock, stress...) in order to ensure the plant optimal growth in its environment (Debono and Souza 2019) [11]. As a result, the EPGs - whose power density spectrum (PSD) and mathematical analysis of autocorrelations respectively show a distribution according to the power law -, SOCs and nonlinear dynamic behaviors include different patterns and colored noises. These values depend on the type of stimuli (cold, low light, mannitol) as well as on temporal correlations on large scales, indicating the treatment of complex information emerging from different temporospatial patterns propagating at the level of the whole plant [9]. 


\subsection{The Bioelectrical Continuum: Rule in Plant Behavior}

Without going back to the pioneering works of Darwin, Burdon Sanderson and particularly Bose (The nervous mechanism of plants, Longmans, Green \& Co, 1926) at the level of plant bioelectricity, modern electrophysiology presents a range of bioelectric potentials well defined in the literature at the cellular or multicellular scale [12], but much less at the level of the whole organism. In this fiels, EPGs have long been considered as noise or non-physiological activities for contextual reasons (linked to the so-called 'Backster effect' in the 80th), which has had the consequence of stopping this field of research and the questioning relating to it for about three decades. The questions I asked following my first discovery of the EPGs (published in 1992) like some researchers such as Pickard or Karlsson (see refs. in [5]) are still relevant today. By what mechanisms are plants capable of constantly analyzing and scrutinizing the space and the environment that surrounds them? How do plants manage to sort such a quantity of signals in real time, some of which are relevant and others not? Are they not saturated with these informations and what kind of perceptive level is in use? The answer given in the light of our recent work is that the permanent emission of spontaneous EPGs is a reflection of effective monitoring systems, reactivity and discriminatory filtering in front of permanent stimuli and stress that the plant fixed to the ground in a singular environment can only undergo (Debono 2013, Souza et al., 2017) [6, 10]. They thus constitute a decisive part of the spectrum, defined as the set of the ionic dynamics of the bioelectric spectrum delivered by a given plant (its specific signature) or a population of plants (De Loof, 2016, Toledo 2019, Souza et al, 2017) $[1,2,10]$. They can synchronize and spread over a long distance at the level of the whole plant, thanks to network activities, thus sustaining high perceptive and communicative levels [7].

Several teams have recently automated the classification of EPG-type electrophysiological activities including variations in extracellular potential and the emission of spikes in real time following various stimulations or stresses by mathematical modeling or using machine learning (Pereira et al. 2018; Tran et al, 2019) $[13,14]$. They reveal, thanks to the use of specific electrodes, the interest of the practice of monitoring in real time the physiological activity of plants without Faraday's cage, which could be applied with success using EPGs. Used as monitoring kits in fields dedicated to agriculture or agronomic studies, they would indeed be able to inform the observer of the physiological changes of a given species or individual and of the mechanisms of propagation of the bio-molecular signals. It concerns particularly wounding potentials or slow wave potentials, which have a hydraulic component and can go in both directions of the plant axis [stem-leaf/up-down] or exchange with the medium. These operations can be used to measure the surface potentials of the leaves and their long-range propagation after injury (Mousavi et al., 2014) [15] or be parameterized by mathematical models of simulation or learning and electrical circuits mimicking biological responses in natural conditions.

Moreover, a recent publication (Simmi et al. 2020) that we will detail later [98], showed, as it was previously the case for osmotic stress [9], that infection with pathogens affected the dynamics of the electrome, and that these alterations, which could be located far from the site of infection (thus implying the propagation of long-distance signals during plant-pathogen interactions), were detectable by EPG before the visible effects of infection on tomato plants. This study validates the interest of EPGs as in situ diagnostic tools, but above all indicates the active role of this electrogenesis in the sensory area of the whole plant. It is thus now a question of advancing on these tracks and in particular on the role of the electrome, considering plants as subjects able of modifying their biodynamism and their behaviors depending on the stimuli, which means to have an access to the experience (or reality) whose degree of cognition should be precized.

Be that as it may, we have already shown following the work of Souza et al. that the permanent spontaneous emission of EPGs within the electrome largely favored these transfers by constituting a permanent monitoring system and threshold clipping or discrimination via self-organized critical systems (SOCs) linked to the emission of oscillations or spikes according to a power law. Our working hypothesis is therefore that this permanent discriminatory management of environmental stimuli allows the establishment of extended or embodied cognitive exchanges that ensures the plant's balance, its growth, its communication and its exchanges with the environment in response to biotic or abiotic stimuli, its possible formation 
Marc-Williams Debono

Electrome \& Cognition Modes in Plants: A Transdisciplinary Approach to the Eco-Sensitiveness

of the World

of symbionts and its rapid adaptation to new situations or stress, parasitic or microbial attacks. This presupposes self-recognition in a competitive environment, benefit-cost analyzes, internalization capacities and operational choice among the informations collected (improve resources, grow optimally, avoid danger, colonize or not, etc.) and problem solving in a given environment. More generally, the results of our pioneering work [5] republished in 2013 in PSB [6] and new approaches in collaboration with the team of Prof. Souza from the University of Pelotas (Brazil) [11] support the hypothesis of a vegetal cognition by showing that a behavioral unit - which is not taken for granted in plants where the process of individuation is not a key factor in evolution - can be observed via hypersensitive integrated biological systems anchored in the environment. If chemical communication is fundamental in inter- as well as intra-species exchanges in plants, our working hypothesis is that the bioelectric continuum provided by continuous EPG surface monitoring (EPGs) and its underlying synchronized networks allows us to link active perceptions, although not conscious with actions. In other words, they would play the role of pseudo-innervation acting both on the surface and within the various plant tissues and membranes. An important fact, which, if it turned out to be proved, could explain the gap between autonomy or certain observed behaviors (whether they are qualified as sensitive, intelligent, or even conscious) and the absence of centralizing structures in the different plant modules. There is therefore a contradiction between a modular anatomy that does not require a pilot and access to experience, although often requiring marked reactivity, and operational choices outside the scope of classical adaptation.

\section{The Mesological Plasticity of Plants}

It emerges from this permanent management of the flow of sessile organs, a perception-action loop, cognitive abilities (Calvo 2011, 2017) [16,17] or intelligent behaviors (Trevawas 2014), [18]. It recently became the subject of an in-depth examination concluding to the benefit that this brings them in natural or real-world conditions in terms of sensory coding, learning, directed individual variation and adaptability (Calvo et al. 2020) [19]. Plants Intelligent behaviors and goal-directed changes (but also bacteria's and unicellular organisms) to face adverse or competitive environments are indeed considered by the authors as the best response to adapt and improve their survival. These elements make plants unmatched autonomous biosensors capable of interacting directly with their natural environment and to be almost inexhaustible bioenergetic tanks. They indicate that the individual variation probably sustained by learning mechanisms is not purely random within a repertory of characters inherited by the plant or resulting from the only natural selection (that Darwin who published The power of movements in plants in 1880 - John Murray, London, considered as operating at the level of the individual), but well related to the plants plasticity that we are dealing with through an active process.

This 'intentional' behavior links here to complex adaptability (learning, memory, competition and regeneration processes... and not the molecular or genetic background, itself linked to quantitative adaptability only) but also to intelligence, differentiating their mechanisms of action at the level of animals or humans and plants, even if they use the same kind of electrochemical communication and functions (perception, sensory inputs, hormonal system, growth, reproduction, development, memory, learning or cognition maps described here for niche construction..). These assumptions validate low voltage potentials using power law relations and bioelectrical protoneural networks [6] as early activity markers and/or diagnostic tools usable in the field as much in agronomy or agroforestry, as for the detection and discrimination of the stimuli when dynamic coupling occurs via SOCs between the plant and its environment $[10,15]$. Equivalent to a radar or watch system, they would allow plants to prioritize or better manage warning or defense signals (and therefore their survival) via hormonal or biochemical responses while saving energy and preserving optimal growth.

As recently published, in this context, we assimilate plants to plastic interfaces having an "electromic" nature (that is to say using primarily the electric dimension of life) [2] and that can display cognitive abilities (in the biological meaning of the term) into interactive ecosystems [11]. In addition to facilitating the transfer of information via membrane bioelectric networks and ion channels or symplasmatic gap junction, 
this ability to discriminate and respond quickly and efficiently to environmental stimuli on the scale of the whole plant, would avoid the mobilization of sub-structures and could explain the apparent functioning unit of the plant, especially in face of a new situation, despite its functional modularity, its impermanence or its versatility and its non-individuality. Indeed, the signature of the plant electrome is inextricably linked to the ternary complex [plant-environment-world] which means a developed sensitiveness, an anchored plant body and a mesological plasticity (Debono, 2020) [16]. However, the management of these flows takes place precisely at the plant-environment interface, which is distinguished by its locality and its singularity of exchanges with the environment. As we have recently shown it, plants are hypersensitive ecoplastic interfaces to the environment, defining a form of plasticity that is neither purely phenotypic nor epigenetic, but mesological $[11,1]$, that is to say an intrinsically and inseparable subjects (and not an automata) from thier local ecosystem. This hypothesis is linked to the ecophenomenological approaches of Berque who establishes for living systems, a matrix-imprint relationship or medial relation between the being and its environment subjected to trajection. It is a continuation of the work of von Uexküll on the Umwelt and of Watsuji on the fûdoron (Berque, 2014) [26, 27] taking into account the status of plant-subject registered in a singular milieu and its dynamic coupling (or mediance) which fundamentally presents a trajectory nature. The mesology or "science des milieux" (Umweltlehre from von Uexküll in opposition to raw environmental data) is indeed detached from the scientific ecology (objective environmental science from which the observer is external) and has mainly had as subject of study, the relations between animals or humans (defining an "ecoumene" following Leroi-Gourhan's work in Berque, 2008) [28] and their environments.

For the first time reported about plants by Debono $(2016,2018)[12,17]$ who adapted the concept of plasticity (Table 1 ) he developed $[29,30]$ to their behavior (i.e. developing a mesological plasticity), that highlights the plant body anchored in the soil (Table 1). This body anchored to the soil being typically medial (that is to say dynamically coupled to its environment), and the evolution of the plant-environmentworld system being trajective by definition (that is to say neither subjective nor objective), but linked to a process of transfer between the raw environmental data (the Umgebung of Uexküll) and the lived environment (the Umwelt) of a given subject [27]. Finally, plasticity can only be integrated into it by nature by being situated in the "as-is" (where the slash of the "as-is" signifies that the trajection and plants can act as interacting subjects with their natural habitat) of the equation $r=S / P$ where $r$ is reality, $\mathrm{S}$ the logical subject (here involved) and $\mathrm{P}$ the predicate (Berque, 2016) [31]. Plants can therefore interact as subjects with their singular environment or their natural habitat, and mesological plasticity plays a major role in this trajection by allowing plants to directly interpret the signals of the environment without resorting to a brain, just like their unique ability to transform light energy. This direct interpretation is at the source of emerging behaviors that we can qualify as intelligent, but which define for us very precisely a cognitive access to experience, in the mesological sense of the term (Table 2).

\subsection{Plant 'Intelligence' and Sensitiveness: Why is All This Possible Without a Brain?}

If this hypothesis was adopted, added to the sensible vs sensitive nature recently admitted by the scientific community about the sensory system of plants, it would constitute a big step in our classification of the living kingdoms and in the modeling of sensory perception modes [34]. This could help solve the apparent conundrum of cognitive scales disproportionate to the size of the brain of animals like birds (recent works show that the delta observed between the small size of the brains of birds and their high cognitive abilities are probably due to a high density of neurons: see Olkowicz et al. 2019) [28] or lemurs having relatively small brains for primates (Fichtel et al., 2020) [29], without mentioning one of the great puzzles of contemporary science, i.e. the unicellular unclassifiable organisms such as the Polycephalum physarum that are able to execute high cognitive tasks without brain. Same observations in terms of proprioceptive capacities are observed in bacteria, which allows them to recognize surfaces thanks to specialized mechanoreceptors or by pathogens to colonize their hosts (Hug et al., 2017) [30]. This would also explain the effectiveness of the perception-action loop emerging from an eco-sensitive interface - the organism (here the plant) and its environment - considered as the poor relation of the somatomotor universe, as well as its intelligent or 
Marc-Williams Debono

Electrome \& Cognition Modes in Plants: A Transdisciplinary Approach to the Eco-Sensitiveness of the World

Table 1: Comparative study of the concepts of Plasticity \& Mesology (Adapted from Debono,

Cerisy conference,France, 2017).

\begin{tabular}{|c|c|c|c|}
\hline $\begin{array}{c}\text { PLASTIC } \\
\text { INTERFACES }\end{array}$ & $\begin{array}{c}\text { PLASTICITY } \\
\text { COMPLEXES }\end{array}$ & $\begin{array}{c}\text { CO-MEANING } \\
\text { RANGES }\end{array}$ & $\begin{array}{c}\text { EPISTEMIC } \\
\text { PROCESS }\end{array}$ \\
\hline $\begin{array}{c}\text { Matter-Form } \\
\text { Matter-Energy } \\
\text { Matter-Mind } \\
\text { Object-World } \\
\text { Subject-World }\end{array}$ & $\begin{array}{c}\text { Thresholds of active } \\
\text { perception }\end{array}$ & $\begin{array}{c}\text { Metadynamic Systems } \\
\text { Plasticity of the living } \\
\text { Plasticity of the mind }\end{array}$ \\
\hline PLASTICITY & $\begin{array}{c}\text { Co-Inherency } \\
\text { Co-Construction } \\
\text { Co-Evolution }\end{array}$ & $\begin{array}{c}\text { Ternarity } \\
\text { Third included }\end{array}$ \\
\hline
\end{tabular}

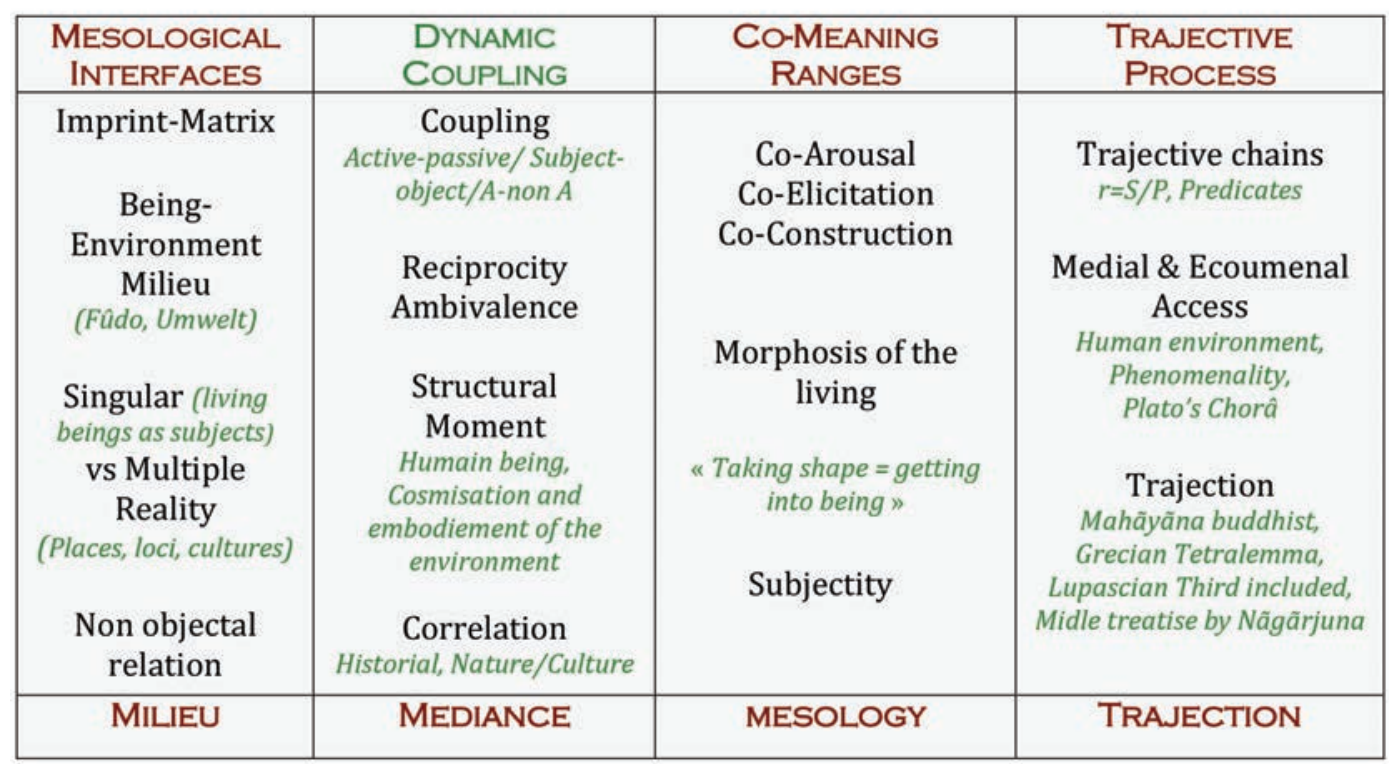

Table 2: Mesological Plasticity.

$1 / \mathbf{r}=\mathbf{S} / \mathbf{P}$ is the mesological relation established by Berque (2016) where $\mathrm{r}$, the reality, is the subject (S) as a predicate $(\mathrm{P})$.

2/ Plasticity would be situated in the 'as-that', i.e. the slash of the mesological relation and any individual or collective subject is supposed to develop its own world.

3/ This 'as-that' incorporate a trajection where Berque (2017) describes a subjectivation of the environment and an environmentalisation of the subject. It can include $\mathbf{P}, \mathbf{P}^{\prime}$ or $\mathbf{P}$ ' predicates assuming: 1- a clear distinction between the living and the machine and an extension beyond the subject/ object dualism; 2- causal and not univocal relationships between the environment and behaviors (a cosmization of the body and a somatization of the world).

4/ This trajective plasticity, added to the notion of subjecthood (in place of subjectiveness) as a proprioceptive or a self-perceptive system with a certain degree of awareness or selfconsciousness depending on the species, allow each living being to be a subject rather than an object. This expanded status may relate to the plant-environment relationship and the modes of plant cognition that we question. 
resilient behaviors (including complex defense, communication or coping strategies). Given the complexity of the surface electrogenic activities recorded in EPGs and their ability to manage external stimuli as well as to represent the synchronized bioelectric networks of different types of tissues or multicellular connections (phloem, xylem, symplasm) distributed over the entire medial body of the plant, we cannot rule out the presence of such dynamic perception systems (not limited to rapid movements in plants but existing at the level of several different kind of perceptions or interpretation of the milieu) or of a minimal integration of input-output or receiver-transmitter signals capable of leading to the co-construction of an intelligible world and/or of a sensible reality.

This is exactly the definition of a cognitive system (not conscious), taken out of its cerebral connotation (Table 3). It is therefore a question, as previously indicated, of considering the 'body-medium-world' entity as the significant reality of a sensible subject (and not only a sensitive one) via a set of reciprocal, emerging and confluent interactions, rather than reattaching it to anthropomorphic characteristics to plants. Intelligent behavior is one, with an added value so strong that it goes beyond the subject but which is necessary to question in a truly transdisciplinary (TD) way [31]. Considering it today outside of a brain, and not only related to the global functioning of nerves or the living is already a considerable step. However, there are two possible approaches if we place ourselves on this unique criterion of an external measure of living subject intelligence, knowing that AI presents characteristics close to human intelligence in terms of information, but that Big data treatments are in no way equivalent to the singularity of biological systems facing the logic of the flows and dataism. The myth of the singularity must indeed be reanalyzed taking into account the specificity of the living (Debono, 2020) [32].

Indeed, plants are undeniably intelligent if we look at them from the point of view of their behavior, their communication or learning capacities, but doesn't it more often come from the intelligence of any living system from the bacterial stage? Probably yes, with different abilities and gradations from bacteria to man implying, or not, conscious systems. Mancuso considers on his side the resolution of problems or new situations by plants as a clear sign of intelligence [33]. However, if we replace this criterion of intelligence by that of sensitiveness or otherness and even more if we consider the purely introspective side of the mind, the prerogative of plant intelligence no longer holds. A point of equilibrium would be to take into account all of the adaptive sensory modalities implying a perceptual link with the environment and able to generate non-centralized global dynamic receptive or perceptive states (GPS) conducing to non-representational cognitive states (see Debono in TJES 4, 2013) [34]. This state could be linked, not to a form of intelligence per se, but to an unconscious access to experience and to the world of the sensible made possible thanks to the medial plasticity of plants (dynamic coupling with their singular environment). More generally, it could be related to an agentive or intellectual behavior in the sense of Averroes [20] and to the field we defined as the mesological plasticity of plants.

\section{Transdisciplinary Stakes Linked to the Plant Sensorium}

The singularity of living systems (Benasayag, 2017) [35], the evolution of nature-culture relationships and the request for an urgent consideration of a sensible ecology (Tassin, 2020) [36] are all arguments justifying the assimilation of plants to autonomous eco-sensible plastic units which perceive and process for their benefit and in real time a whole set of environmental information and data without resorting to animal or human intelligence [11]. For all these reasons or conjunctions, we will admit that the result of this complex and interactive biodynamic process may be sufficient in itself. It authorizes de facto an access to observable experience at the scale of the whole plant or of a given species subject to a singular medium and to environmental stimuli, without the need to resort to metaphorical arguments or transposition. We thus see that one of the main problems facing researchers in their positioning as regards the sensory capacities of plants is of a semantic nature. 
Marc-Williams Debono

Electrome \& Cognition Modes in Plants: A Transdisciplinary Approach to the Eco-Sensitiveness

\subsection{Semantic Traps}

Following the current of thought of plant neurobiology (Brenner et al., 2006 Baluska et al. 2006) [37 a, b], it does not seem to be necessarily a matter of recreating new words, although this would in itself be rather beneficial for the scientific community, but rather of trying to strictly balance existing terminology (neural attribute, sensitiveness, intelligence, behavior, cognition, sentience, awareness) by using it wisely. The metaphor of the brain-computer compared to the brain as a representation of reality is a good example on a human scale. The use of a vocabulary intrinsically linked to the animal or human condition such as the concept of play, motherhood, compassion or the fact of lending feelings or a mentality to plants is to be banished because false and counterproductive. However, the semantic shift is frequent as the temptation is strong and the behaviors comparable. For example, physical evidence of the increase in a maternal hormone, auxin (among other signals), during the development of the plant's embryo (Robert et al., 2018) [38], or even sending chemical messages between plants using volatile molecules are undeniable scientific observations. To conclude that plants "mother their children" or "warn their neighbors" as some authors mediate is an abuse of language. Neural similarities shared by plants and animals are clear, however, as noticed by Msimang [39] the implicit recognition of Brenner, Calvo and other authors about the school of plant neurobiology, is that we are here more faced with a disanalogy than an analogy (ex: memory assimilated to a basic process like in the immune systems or to a real encoding of information with propositional effects) and the turning point taken by this discipline (plant signaling and behavior), which is at the origin of a recognized and prolific field of research, is directly linked to this observation and to the Alpi controversy previously mentioned. It is a question of determining to what category of behavior we are dealing with: a purely computational model of information processing, a direct perception with cognitive access to the experience, or even an eco-psychological model (Calvo 2017) [40].

In the same way, aforementioned taxonomic approach of Sterelny about control system categories can help guide the debate [55]. However, as I previously mentioned it, taking as model a neuronal plant or a brain-like system seems to me counterproductive. While building blocks and evolutionary stages common to all living beings are evident, the divergence of the plant-animal kingdoms has led to different defense, survival or adaptation mechanisms. If we follow the course of time of evolution, it is not surprising to note that certain ionic channels present in the bacterium are still effective and that plants have developed protoneural systems [6], which were used for the development of future brains. However, this in no way justifies that the cerebral metaphor applies to plants and that they have the need to centralize information or to show intentionality in their actions.

On the other hand, their anchoring to the ground, their increased sensitiveness in direct link with the environment and the natural elements has undoubtedly brought about the emergence of intelligent ecosocial behaviors in the literal sense of the term which are related to forms of cognition "neither inferior nor superior"... but singular. Seeking to animalize or humanize them is futile. Conversely, to consider perception as isolated from action and a minimal degree of interaction seems nonsense to us. For Alva Noë [41], contrarily to neurocomputationists like Churchland [42], perception is not a process originating from the brain, but a form of activity concerning the body as a whole. In line with enactivits or neurophenomenologists like Varela and Thomson [43] or Di Paolo et al. (2010) [44], the author tells us that we are enacting our perceptual experience. However, the autonomy and hypersensitiveness of plants - now evident and accepted by the scientific community, which is not the case with intelligence - are precisely undifferentiated experiences of the plant body in relation to its environment.

The key word here is experience which, linked to observable behaviors at the macroscopic scale, implies not a centralization as at the level of the nervous system, but another type of apprehension of reality or access to unconscious experience, (in the sense that we understand it with animals or humans), not limited to pure reactivity, i.e. the ability for plants to perceive their shapes, their deformations, their aggressors, theirs congeners and to give, not only existent tailored answers, but highly complex and interactive ones. Is it all about intelligence? Not necessarily, although we can clearly see here the limits of our vocabulary and the difficulty in finding a terminology which is capable of describing similar and different qualities at the same time (living intelligence and awareness: possibly, mental or introspective intelligence: no). 
That said, sensitiveness or the information-driven behavior criteria taken in isolation are insufficient for us. It must be necessarily accompanied by an access to experience (as minimal as it is) and a loop of perception-action-feedback via a cognitive or enactive system (revisited by many authors like Calvo (minimally cognitive systems, sentience) $[40,45]$ or Trevawas (intelligent behavior, ubiquitous systems) [46, 47] (Table 3).

For us, the plant cognitive dimension is not yet qualified because we are starting to explore it only according to criteria from animal or human biology (see next chapter) or in a strictly "neural way", either not taking into account cognition without representation or mental states, or using a phytoneuronal semantics which muddies the tracks for the neophyte. What seems to us to be taken for granted, is that vegetal cognitive states are highly supported by the electrome (preponderant dimension acting sometimes in synergy with, but often differently to the chemical pathways) and a set of non-localized somatotopic properties favoring its deployment on the scale of the whole plant body. This synergetic perceptive apparatus involves cognizing agents directly acting upon the plant sens orium, i.e. the totality of sensory reception and experience involved in such an open exchange between the plant body and its environment [34].

According to this point of view, the signature of the electrome would reflect, not an intelligent system in the introspective and representational sense of the term, but a cognitive system in its post-cognitivist meaning of access to experience or awareness. This last meaning differs from a computational intelligence being disembodied and linked to informational treatments of the information, as notably shown by the work of Maturana and Varela in the West [48, 49] - operational cloture and auto-poïesis, cognition theory, embodied cognition and enaction - [43] and by the mesological assumption of a mediance and a co-extensiveness between living beings and their milieu - different from the environment as raw material (Berque, 2019) [50]. All living beings present this type of cognition, different from the neural one, from the unicellular stage and at varying degrees of elaboration, which is inherent in any form of perception and essential to survive in a changing environment. However, hypersensitiveness to the milieu of trees and the permanent struggle between modularity and active plasticity of the plant body are two essential factors for the survival of plants in an often hostile environment. They define an otherness specific to plants, with its codes and identifiers (sessility, divisibility, autotrophy, slow mobility, modularity, decentralization, direct interactions with the elements...), rather than cloned or superimposed on an animal or human identity (inseparable from rapid movement and nerve centralization).

\subsection{Behavioral Activities and Perceptive Levels in Plants}

Let us take concrete examples: Codariocalyx motorius or Desmodium Gyrans is genetically programmed to move its leaves to capture the maximum of light present in its natural environment (undergrowth in tropical zone). We can also see that it requires learning to respond more and more efficiently with identical sequences of complex movements to the sound vibrations without fully understanding the sensory mechanism involved. Research continues about the nature of this sensitiveness to sound and about these consecutive erratic rapid movements; some hypotheses point to a possible mimicry of the rapid rotation of a butterfly wings by their leaves to fool its predators (Lev-Yadun, 2013) [44]. Most plant species react in a graded manner to stimuli by making their leaves unappetizing to toxic by making tannins, for example, depending on the type of herbivore or threats encountered. A lot of others like Pisum sativum or Arabidopsis thaliana have advanced management strategies related to decision-making or growth for the various stimuli that reach their roots (salt gradients, osmotic shocks, stress, presence of competitors, distribution of resources, etc.). Mimosa pudica, of which the mechanism of motor reactivity is well known, has recently been shown to be capable of serialization and memorization. Indeed, it no longer reacts with rapid movements to reiterated stimuli as soon as they are considered non-dangerous, without it being a 'fatigue' phenomenon, and is able to memorize the nature of the stimuli to which it is subjected over an evaluated period of 28 days (Gagliano, 2014) [86a]. Furthermore, recent experiments presented by the same researcher on pea plants have concluded that associative learning behavior is involved, which could imply epigenetic reprogramming [86b]. 
Marc-Williams Debono

Electrome \& Cognition Modes in Plants: A Transdisciplinary Approach to the Eco-Sensitiveness

of the World

Another example of astonishing mimetic polymorphism, the South American chameleon liana Boquila trifoliolata, capable of imitating the plants on which it climbs, allowing its leaves to take a great diversity of forms and sometimes several at the same time. Finally, in addition to the clearly established perception of gravity via the statocysts, and around twenty other senses, trees display memory, adaptive and proprioceptive behaviors when they are subjected to violent stimuli (wind, fire, torrential rain). Actually, proprioception or the ability to feel its shape and/or its bodily pattern and potentially those of others (example of canopy, morphogenesis and/or active responses of trees and plants to stimuli like wind or gravity), concerns the entire plant body which responds to it in a biomolecular way. This happens by the action of growth factors, notably at the level of the meristems, and, with certain mechanical, geometric and/or morphological constraints, which do not prevent their control from the scale of the whole plant. This indicates a degree of perception of a cognitive type hitherto unheard of in plants, in particular when it affects posture control (via the statocysts) and resilience, which requires adopting a much more integrative view of the development of the living (Moulia and Fournier 2009; Hamant and Moulia, 2016) [53, 54].

\section{Frontiers in Cognition: A Comparative Study of Neural vs Non-Neural Systems}

\subsection{The evolutionary Taxonomy of Cognitive Control}

Before opening the debate on the possible operating modes of plant cognition, it is important to specify the criteria delineating plant cognition (Table 3). In this way, an interesting study developed by Sterelny in 2003 [55] about the evolutionary taxonomy of cognitive control was recently presented by Msimang [39] as a possible method of establishing general principles discriminating what cognitive abilities that are or are not at play in plants. Indeed, apart from their adaptative responses to environmental cues and their active control of growth or development, Msimang highlights Sterelny's taxonomy in the evolutionary sensitive context of plants. This approach takes into account the complexity of the environment and the fact that cognition is above all a mechanism for controlling behavior. In this regard, the author cites the work of Godfrey-Smith (2002) showing in particular that species subjected to the same selection pressure manage it differently depending on their evolutionary lineage and their ability to adapt. It is therefore a matter of classifying the different types of behavioral control, which Sterelny does by describing three main types of behavior: 1/ detection systems (flight responses, tropisms), 2/ robust tracking systems (transparent environments, hostility of the predator-prey relations), $3 /$ the response breath including false positives or negatives, internal signals and informational complex systems and 4/ the decoupled representation (represented targets, environmental features not coupled functionally to specific responses, trial and error, mimicry) often describing animal or human cognition, and possibly some "neurobiological" aptitudes of plants.

These criteria are used in Msimang's paper to define "how cognitively able plants are as intelligent agents" (quoting Legg \& Hutter 2007) where intelligence is assumed to be used by many authors in the same way as cognition in the context of the semantic war that scientists and botanists wage over metaphorical language or borrowed from neuroscience (e.g. emotions vs. sensitivity, consciousness vs. awareness, etc.). However, the Sterelny method makes it possible to get out of this impasse by qualifying the heterogeneity and the complexity of the environment as well as the conditional nature of the adaptive responses or of the phenotypic plasticity of plants. Msimang gives the example of the Venus flytrap of Dionea M. as a robust animal-like tracking system indicating that the sophistication of some of the behaviors of plants can be achieved with relatively simple modes of cognition. He also deduces that the fact that plants do not have a type 4 cognitive control, that is to say representational, disqualifies them as having consciousness or awareness.

These criteria clearly delimit the behaviors we are dealing with, by differentiating for example the functional criteria from the causal criteria-the definition of an intelligent system depends on it! - or by examining the contingency levels of discrimination systems (often adaptive) and by relating them to 
behaviors strictly qualified as functional. Plant behaviors using chemical, metabolic or electrical pathways, proprioception, stored information that can be recalled or learning, clearly display cognitive processes that can be graded and differentiated from machines or AI. Msimang analysis notes that strictly following Sterelny's classification, the two last criteria are not necessary conditions compared to detection systems). However, it doesn't mean that plant does not have intelligent behaviors but that "...particular kinds of controls are outside their purview". He argues that some of the plants have minimal cognitive systems using simple detection operating on cues and not on memory (like autonomous machines) whereas others present robust tracking systems depending on the integration of several parameters, and more generally that "plant display an array of adaptive responses, but only a subset of these responses can be classified as behavior" [39].

Numerous examples of cooperation, mutualism or mychorizial (and bacterial) symbiosis leading to interconnections with the root network and intra- or interspecific exchanges developed over huge areas are also widely described in the literature (Simard, 2012) [56]. They allow a wide communication between plants and trees of the same species or different species. As a recent example of mutually beneficial relationships, Conospermum, a plant that has developed a way to use ants to its advantage, like the pollinators overcoming their antimicrobial defenses, a mechanism as effective as the action of native bees! (Stock et al, 2020) [57]. This is the first finding of such a cooperation mechanism, even if "it would be risky, in an evolutionary sense, for the plant to rely only on the native bee for pollination" say the authors. To these considerations could be added Margulis'involutive hypotheses (endosymbiosis and...) regarding cooperation and mutualism as a sufficiently frequent mechanism in inter-species relations to oppose the classic evolutionary thesis based on a preponderant and generalized competition (Margulis et al.) [58, 59]. Finally, the incessant discoveries of unknown taxa, such as the Langsdorffia holoparasite recently indicate that each plant-environment pair corresponds to a form of sensitiveness and direct cognition between the organism and its environment (Thoroggod \& Santos, 2020) [60].

This ecosystemic cognition calls, as for many species (fungi, insects, marine animals...): $1 /$ to selforganization and reciprocity or biofeedback mechanisms characteristic of living systems (Maturana, 1980) [48]; 2/ to a perception-action loop and emerging behaviors specific to non-neural organisms such as plants, fungi or physarum polycephalum, or neural and having a complexity inversely proportional to their functionality as in the case of the Octopus; $3 /$ to forms of minimal (tropisms, information-processing systems, epiphenomenal (Calvo, Garzón) [45, 61], embodied [43], distributed (swarm or colony) or extended cognition when it comes to communicating on a large scale and over a long distance (via root networks and mycorrhiza) and even to cognizing agents constituted by action-oriented feedback mechanisms like those supported by the skin-brain thesis (Keijzer, Milkowski 2017) [62, 63]. Developed by Keijzer in opposition to the classical reflex arc of pain described by Descartes, this approach shows that it represents probably a secondary adaptation and that biological information processing can occur without CNS in early organisms. Consequently, he describes the myoepithelium or an excitable epithelia using chemical signaling as a primitive conductive element able to transmit information through neuromuscular junctions and motor coordination before the evolution of nervous systems (Keijzer, Wiljes et al. 2015) [64, 65].

This thesis supported by Parkers' phylogenetic work about elementary nervous systems (1919) [66] is important because it admits two consequences corresponding to our pioneering discovery on plant spontaneous Kalanchoë electrophytograms (Debono \& Bouteau, 1992) [5]: 1/ the presence of a spontaneous activity capable of supporting self-organized whole body organization; $2 /$ the generation, at the same level of description of animal protomyocytes or neuromuscular processes (Mckie, 1990) [67] and of plant dynamic protoneural networks (Debono, 2013) [6] forming coordinated patterns of activities (illustrated by Wiljes for the tube-shaped animal model) [65].

Milkowsky (2017) also quote the recent hypothesis of Arendt (2015) [68] suggesting an apical (controlling the whole body physiology) and a blastoporal nervous system (feeding movements and locomotion) nervous system, differentiating external (reflex) from internal coordinated multicellular activities, specifying that "the claim is not about the current organization of the nervous system; it's about its evolution", which means that: "early stages (that could be related to property detection)... need no sensory contact with reality to produce minimal cognition". This minimal cognition often presupposes a receptor-effector link and a reflex 
Marc-Williams Debono

Electrome \& Cognition Modes in Plants: A Transdisciplinary Approach to the Eco-Sensitiveness of the World

arc architecture that was able to evolve towards an internal motor coordination. However, different sensory modalities can drive to different reactions depending the nature and the plasticity of the substrata (brain, plant or bacteria). For instance, the phenotypic plasticity of plants is highly significative for their growth and development in a hostile environment while the sensorimotor coordination of animals is essential for their survival. Another consideration linked to our previous description of the mesological plasticity of plants and the sensory flows they need to constantly treat on line (Debono, 2018) [17] is the Gibsonian contextualization of sensory organs vs receptors where the firsts are described as active parts of perceptive systems (including proprioception recently developed by Moulia et al. [54]) while the seconds are fixed informational and/or recording systems (Gibson, 1966) [69].

Milkowski (2017) rightly underlines in his paper that the "organism may stand in a non-informational interaction with the environment without any sensory reception, or more, without any information detection", and that we can differentiate information-based-causation (like DNA machinery) from other transactions. Amebas are cited as unicellular examples having no dedicated sensory receptors but coordinated behaviors, contrarily to skin-brain models having no discriminative abilities, so no sensory detection, regarding their external environment. His main conclusion are that in that case "there is no ecological meaning of the internal signals, and the proximal signals do not seem to carry any distal information event about the Innenwelt of the skin-brain animal", which matches our argumentation about ecoplastic plant interfaces and their dynamic and trajective character, in the mesological sense of these terms [11] (Table 1-2). More generally, the author assumes that the function of the central nervous system (CNS) itself has changed over time in most organisms and that "the sensory experience, or even any reliance to the senses, is not required to make a piece of information knowledge for a cognitive agent". It means that unlike the CNS which evolved for motor control in animals and humans, minimally cognitive processing linked to evolutionary earlier nervous systems like bacteria or plants may have evolved without any senses. More accurately, the author defines the "epistemic primacy of sensation" as related to meaning or knowledge (based on sense experience or conceptualized from it and not linked to conscious experiences) and explains that minimal cognition can occur without sensory experience. Knowledge is here possible without sensation, whereas sensory reception is a necessary step to reach knowledge.

Anyway, for us, the question to be addressed is how the dynamic coupling of plant and the environment permits a cognitive access to the experience of reality? And what kind of cognitive abilities or behaviors is put into play? To answer these questions about the cognitive nature of plants, we suggest the study of the ternary link 'plant-environment-world', excluding to separate the body, not from the mind, since the question does not arise here, but from its cognitive and terrestrial matter (or habitat). Overall, it is a question of taking into account the different levels of organization, sensitivity and reactivity with which living systems evolve according to their specific ecoplastic interfaces, and of redefining the frontiers of cognition as regards non-neural organisms and plant cognition in particular.

The protoneural dynamics of plants that we have previously described with regard to the EPGs recorded in Kalanchoë D. [6] does not indicate at all the development of a "neuronal plant", but the establishment during evolution of common biochemical and genetic cellular mechanisms to all living systems (like bacteria's ion channels) which would gradually differentiate to lead to synaptic plasticity of the brain in animals and humans. All in all, the prototypal character of plant cells that appeared before the emergence of the nervous system of invertebrates, vertebrates, and then primates, explains their indissoluble links, as well as their fundamental differences linked to the divergence of kingdoms during evolution. Among these essential differences, the modularity and the pluricentrality of divisible, iterative, autotrophic and almost immortal plants in front of the uniqueness, centralization, indivisibility and heterotrophy of the animal kingdom. Both kingdoms show indeed to far degrees, sensitiveness, movements and forms of cognition ranging from access to experience to sentience in plants and from immediate consciousness to introspection and self-awareness in primates or man. We therefore find ourselves today logically having to explain the gap between perception and integration of brainless systems that have evolved differently and that demonstrate complex, sensitive behaviors according to certain intelligent criteria.

In order to calibrate the nature of plant cognition, understood as a process of knowledge of the environment with semiotic value or knowledge accumulating systems [11] compared to that specific to 
animal species such as birds or insects whose delta between the size of the brain and the cognitive complexity noted is very large but can be explained in other words (density vs extensiveness: see 5.2), we refer to the three classic cognition categories. This is namely: $1 /$ the distributed cognition where it is the multiplication which creates a form of collective intelligence typical of colonies of ants or other insects and animal or human societies; 2 / the situated or embodied cognition, linked to the preponderance of a peripheral part of the body (octopus tentacles etc.) and in humans the non-prevalence of the brain on the body, $3 /$ the extended cognition that goes beyond the body (spider web, AI in humans, etc.). Other forms of cognition can be brought into play depending on the species and the categories (Table 3).

\subsection{Small Brains, Great Cognition}

Comparative approaches between plants and animals consists in detailing the differences between the cognitive modes of small vertebrate species compared to biggest animals or man. Indeed, a recent study of the brains of 28 species of bird brains (parrot, magpie, crow, wren, jay ..) published in PNAS (Olkowitcz et al. 2019) [28] presents the high cognitive capacities and similar to the primates of many birds (construction of tools, decision-making, complex learning and language, self-awareness) despite their small size. This study shows that this would be due to the density of their neurons, 2 to 4 times higher than in certain mammals. The researchers' hypotheses on the cognitive performances and the levels of intelligence observed lean for different evolutionary strategies depending on the species: long-distance connection in the brain of mammals vs increased density of neurons in birds, which would make them win in weight/brain mass ratio (advantage for flight). In insects, tiny brains are not only dense but thrifty, allowing them to process a large amount of information in real time (although it is much less efficient than that of higher animals in terms of memorization or abstraction) and in a minimum of space despite their limited number of neurons (hence lower energy expenditure unlike mammals and humans: 20\% energy expenditure) [28].

As previously evoked for lemurs, primate brain size does not predict their intelligence. Although we are discussing cerebral species here, the consequences of this weight/energy ratio on the degree of cognition involved are interesting to be taken into account in our context, because they indicate the crucial importance of phenotypic and epigenetic plasticity in evolution. Related to affordant systems and mesological niches, signs make indeed possible to interpret the relationships between the perceived signal and its response in terms of efficiency and biosemiotics. For instance, there is no doubt that a bird interprets a horizontal branch on its way as a natural perch, which will not be the case with other species such as small rodents, insects, or even climbing plants or roots that will have to avoid or bypass it. In another context, the bird, to make its nest, will use the twig.

Let us return now to plant cognition, Parise et al. [70] show with regard to extended cognition, that when the spider weaves its web, it is all its body that becomes an extension of the environment and that external physical objects are part of the cognitive system of the animal or that it can handle them. This is also the case with bird nests to a lesser extent, and tools made and used by certain animals, notably primates with tools and humans with the development of writing and now AI. Each time, cognition goes beyond the apparent limits of the organism in its own environment. The authors go further than this observation, specifying the need to establish criteria for mutual manipulation in order to eliminate false positives (temperature, blood oxygen, physiological constants, etc.) and to consider the cognitive system spider + web. In fact, the responses of the spider are totally conditioned by the tension of its web and the vibrations perceived by its CNS. The spider therefore developed an increased sense allowing it to discriminate the vibrations associated with various stimuli like the wind or the presence of insects. If you artificially change them, you completely change its understanding of the world. The authors hypothesize that plants could offload part of their stains by extending their cognition and the areas of influence of the roots far beyond their body thanks to the mycorrhizal network and the rhizosphere, especially during the perception of obstacles linked to the accumulation of allelopathic exudates between the two elements: the roots and the physical obstacles detected. This leads to inhibition of root growth in the direction in which these exudates are accumulated and therefore a mean to bypass them. Same observation at the level of bacterial exchanges where we find this manipulative behavior benefiting plants with respect to the 
Marc-Williams Debono

Electrome \& Cognition Modes in Plants: A Transdisciplinary Approach to the Eco-Sensitiveness

of the World

microbiome of the rhizosphere: example of triterpenes of specific Arabidopsis bacteria, of the amplification of the perception of mychorrize fungi to favor the exchanges or the uptake of water, and nutrients and phosphorus photo-assimilated elements of plants. This indicates that the fungal network extends the perception of the environment by plants and facilitates their cognitive processes such as memory.

The criterion of mutual manipulation is therefore a good model of cognition via an organism rather than a physical object and can be extended to another organism of a different kingdom [70]. It supports our model of the plant as ecoplastic interface and considering the dynamic coupling of the plant and its environment (milieu) as inseparable from its cognitive valence, in part thanks to the electrome that highly contributes to the development of sensitiveness and communicative functions of plants [2, 11]. Other advanced forms of cognition in organisms without a brain, even tiny ones like in the insects or birds that we mentioned earlier, have been described in a protist, the Physarum polycephalum, single-celled organism of the myxomycetes family, which is able of learning and memorizing. A recent work shows that not only does the Physarum learn from its experiences, but that it can transmit them to a congener by fusing with it thanks to a contractile venous system (Actin-Myosin) filled with cytoplasm which allows it to move and grow to record sizes (around $10 \mathrm{~m}^{2}$ ) by absorbing food (especially mushrooms) (Vogel and Dussutour, 2016) [71]. The fusion of venous networks and its ability to absorb/deploy at high speed and over large areas make the "Blob" an almost eternal organism. What interest us here are its high cognitive capacities: solving maze-like problems, creating complex networks (Nakagaki et al. 2000, Tero et al., 2010) [72, 73] and anticipating stimuli (Saigusa et al., 2008) [74]. Some protagonists associate these learnings and the memorization of information with processes inducing epigenetic modifications (Schaaps et al, 2015) rather than with a form of intelligence [75]. However, the long-term memorization of aversive substances after periods of dormancy recently described by Broussard et al. (2019) would imply here a conservation of this habitation and therefore a form of inceptive memory [76].

More generally, the observation of cognitive abilities is far from only concerning rare species of plants. The behavior of many ordinary plants such as the "Ladies' Arabette" exhibiting proprioception (Moulia and Fournier, 2009) [53], the aspen showing mechanoperceptive behaviors following stress (rapid triggering of a specific gene when a branch is bent by the wind remaining memorized for at least a week; Martin, 2010) [77], maize roots exhibiting responses to specific sound frequencies (220Hz) (Gagliano, 2012) [78], volatile mediators like the B-phellandrene or A-Pinene of the tomatoes (Mescher, 2006) [79] and all responses provided by plants facing biotic or abiotic stimuli. Whether they are purely defensive or reactive to new situations, they require complex sensory perception modes and a great plasticity not only adaptive, but minimally developmental, inducing metabolic, genetic modifications and specific bioelectrical mechanisms.

\subsection{Plasticity of the Plant Body and Hypersensitiveness to the Environment}

On another scale, the inter- and intra-species communication developed via the root networks (the Wood Wide Web) and the mycorrhiza of all plants in varying degrees depending on their size and age can reach considerable areas (thousands of $\mathrm{km}^{2}$ for a tree of consequent size) and lead to extremely fine readjustments of the metabolism and the feeding of the terminals as well as to elaborate transmissible defense strategies. The same applies to the displacement of the treetops depending on the light projected and the poplar plantation concerned in the canopy, the complex plant-animal interactions during pollination or the use of second-degree species lures by orchids. Is it a purely adaptive phenomenon, a hypersensitivity to the environment or traces of intelligence? In any case, this justifies questioning the concept of intelligence of the living, even if this term remains subject to questioning and bring nothing in itself, while posing that it would undoubtedly be more relevant to focus on the sensitive and cognitive qualities of plants, more able to reveal their deep nature [16].

We can clearly see through all these exemplifications that the plasticity of living systems is the common denominator of all species, whatever their mode of exploration of the environment [23, 25], but that different modus vivendi emerge depending on each of them. However, it is each time the determination of the dynamics of the organism-environment couple that produces forms of interactions sometimes qualified as sensitive, sometimes cognitive and intelligent. Most of the discussions revolve around the delta between 
the nature of the observed behavior (for instance a form of learning) and its consequences in terms of classification in the cognitive scale, and further downstream, at the evolutionary one. Hence the generation of circular issues resulting in the two types of drifts (semantic and anthropo- or zoocentric) that we know about plants. We must therefore detach ourselves from this sterile problematic. Thus, the generalization of responses involving in certain species (whether animal, vegetal or other) loops of perception-action, cross-communication, recall and/or transfer of stored information and learning capacities is a flagrant marker of the existence of cognitive processes in biology, whether or not these attributes are qualified as intelligent (Abramson \& Chicas-Mosier, 2016) [80]. We have also seen that it was possible to get around the problem of individuality and the macroscopic observation of the split behavior of divisible, decentralized and essentially modular plants, by appealing to the efficiency of complex biodynamic systems such as the bioelectrical continuum at the scale of their different tissues (phloem, xylem, symplasm, etc.). This process extended to a uniform somatotopic mapping - given that the functions are not separated but present in all plant cells - unlike the specialized structures of animals, can compensate for this non-individuation made up of minimal cognitive entities following the description of Calvo and Keijzer [45], because it allows rapid and long-distance information transfers between bioelectric networks via complex excitable structures (like interconnected bundles or vascular tissues including anastomoses;Volkov, 2012) [81] which can be synchronized (Masi et al. 2009, Debono 2013). It is therefore, like the physarum or other somatocentred organisms, the entire plant in connection with its environment, which constitutes a eco-sensible cognitive interface suitable for accumulating information and knowledge, memorizing it for a longer or shorter time and to restore it thanks to its mesological plasticity (active and coextensive binding of the ecoplastic interface, mediation of the plant body and trajection to the plant-environment interface; Debono and Souza, 2019, Debono 2021) [11, 82].

So, let's come back now to the three essential questions dealt with throughout this article: $1 /$ why is 'everything' (i.e. all these cognitive abilities) possible an aneural context? 2/ Where and in what way do the emerging behaviors and the cognitive nature of plants compensate for this lack which is not really one? 3 / What is the nature of the cognition brought into play between the plant and its immediate environment, regardless of the permanent changes to which it is subject? We have largely answered these questions, but at this stage of the description which wants to approach the world of sensitiveness (which is neither a sensitive, nor a sensible or emotive field), too often relegated to the background in human civilization for the benefit of profit or materiality, our answer will be that the links between the plant - to be considered as a subject - and the environment are by nature inseparable and that they determine an unconscious and 'unrepresented' access to experience, but which is very real. It is determined by its hypersensitiveness to the environment and a rich sensoriality, in other words what anthropologists like Morin have described as a 'self-eco-organized' structure [83], post-cognitivist phenomenologists like Thomson and Varela as embodied and/or enacted cognition [43] and ethologists like Watsuji and Uëxkull (see Berque 2019) [84] as a mediance or a dynamic coupling between the subject and his environment (Table 3). Our proposal takes these fundamentals into account, but goes further, in that they explain them: $1 /$ through a precise and operative scientific observation: the role of the electrome or the electrical dimension of plant life (Toledo et al., Debono and Souza, 2019) [2,11], 2/ using a transdisciplinary reading grid.

Indeed, we have shown that the behavioral unit observed in plants is largely made possible thanks to the emission of spontaneous surface variations (EPGs), which constitute, within the electrome, a monitoring system reflecting exchanges between the underlying bioelectric networks and a permanent discrimination of environmental stimuli. In other words, the electrical dimension of the plant life permits a fast and efficient propagation of the information, allowing them to communicate and have a form of cognition anchored in a body, an environment and a world [16] intrinsically linked to their hypersensitive dimension and their otherness. These two components constitute an electromic and eco-sensitive interface linking the whole plant to the plasticity of the world itself [11]. The finding of the operability of what I have called 'mesological plasticity' has direct implications on the interpretation that one gives to the terms of intelligence, sentience, cognition or subjectivity of plants by cutting short sterile semantic or tendentious discussions. 
Marc-Williams Debono

Electrome \& Cognition Modes in Plants: A Transdisciplinary Approach to the Eco-Sensitiveness of the World

Table 3: Comparison of cognition modes in plants.

\begin{tabular}{|c|c|}
\hline & $\begin{array}{l}\text { Cognition / Etymology: "The word cognition dates back to the } 15 \text { th century, where } \\
\text { it meant "thinking and awareness. The term comes from } \\
\text { the Latin noun cognitio ('examination,' 'learning,' or 'knowledge'), derived from the } \\
\text { verb cognosco, a compound of con ('with') and gnōscō ('know'). The latter } \\
\text { half, gnōscō, itself is a cognate of a Greek verb, gi(g)nósko }\left(\gamma 1(\gamma) v \omega \sigma^{\prime} \kappa \omega \text {, 'I know,' or }\right. \\
\text { 'perceive') ".... "It refers to the mental action or process of acquiring knowledge and } \\
\text { understanding through thought, experience, and the senses" [WP]. Several } \\
\text { conceptions of animal or human cognition exist since the development of cognitive } \\
\text { sciences, mainly linked to psychology, cognitive neuroscience, social science, } \\
\text { anthropology and the philosophy of mind considering the body as peripheral to } \\
\text { understanding the nature of mind and cognition. }\end{array}$ \\
\hline & $\begin{array}{l}\text { Plant cognition is nowadays focalized on growth and the determination of the extent } \\
\text { to which plants can use senses and cognition to respond to their environments. The } \\
\text { Plant Neurobiology school of thought assumed in its first acceptation that plants have } \\
\text { physical structures functioning as neurons, synapses or minimal brains (i.e. the "root- } \\
\text { brain hypothesis" presented by Balüska in } 2009 \text { on the basis of earlier Darwin's } \\
\text { work) but is today dedicated to plant signaling and behavior and the study of their } \\
\text { cognitive abilities including perception, learning and memory processes. This } \\
\text { behavioral/ecological approach has a high impact on animal or human/vs plant } \\
\text { intelligent behavior comparisons being defined as an active adaptation and response } \\
\text { to any stimuli presented to all living beings. } \\
\text { - A study of Calvo \& Keijzer about minimal and distributed cognition in plants (see } \\
\text { below) admits } 5 \text { criteria to establish the kind of plant cognition: } 1 / \text { Basic metabolism } \\
\text { (biochemical normativity established in ref. to a study of Barandiarian (2008); } 2 \text { / } \\
\text { Spatiotemporal dispersal characteristics of this metabolic normativity; } 3 \text { / } \\
\text { Spatiotemporal structure of the environment accessed by free and reversible bodily } \\
\text { movement, } 4 / \text { Basic sensorimotor (SM) organization mainly operating online; } 5 / \text { SM- } \\
\text { based cognitive organization considered as cohering unit and not a collection of } \\
\text { individual stimulus-response relations. }\end{array}$ \\
\hline & $\begin{array}{l}\text { Post-cognitivist theory: "The embodied mind thesis challenges other theories, such } \\
\text { as cognitivism, computationalism, and Cartesian dualism. It is closely related to the } \\
\text { extended mind thesis, situated cognition, and enactivism. The modern version } \\
\text { depends on insights drawn from recent research in psychology, linguistics, cognitive } \\
\text { science, dynamical systems, artificial intelligence, robotics, animal cognition, plant } \\
\text { cognition and neurobiology". [WP] }\end{array}$ \\
\hline & $\begin{array}{l}\text { Agency: "In very general terms, an agent is a being with the capacity to act, and } \\
\text { 'agency" denotes the exercise or manifestation of this capacity. The philosophy of } \\
\text { action provides us with a standard conception and a standard theory of action. The } \\
\text { former construes action in terms of intentionality, the latter explains the intentionality } \\
\text { of action in terms of causation by the agent's mental states and events...". } \\
\text { Agency without mental representation: "...there are beings that are capable of } \\
\text { genuine agency and that do not possess representational mental states... It is, for } \\
\text { instance, compatible with what Barandiaran et al. (2009) call "minimal agency".... } \\
\text { "This view departs from the standard conception and theory in its characterization of } \\
\text { action ("doing something") in terms of the "adaptive regulation" of the agent's } \\
\text { "coupling with the environment" and in terms of metabolic self-maintenance } \\
\text { (inspired by Varela et al. 1974). They suggest that organisms as simple as bacteria } \\
\text { exhibit this minimal kind of agency. The crucial point is that this provides an account } \\
\text { of goal-directed behavior that does not appeal to the mental representation of } \\
\text { goals...". [SEP] } \\
\text { Situated cognition: Agent vs environment. }\end{array}$ \\
\hline & \\
\hline
\end{tabular}


Table 3: (continued).

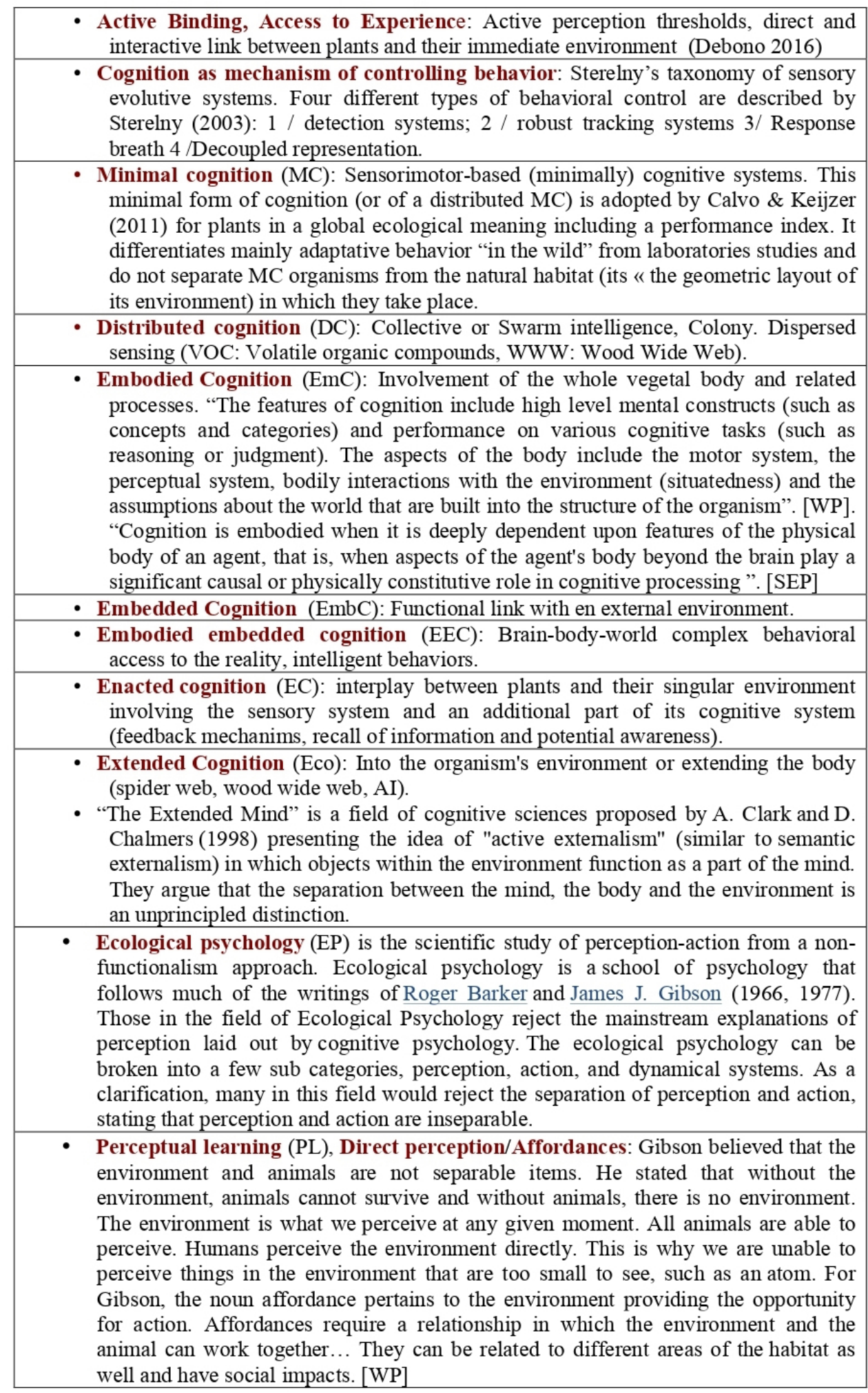


Marc-Williams Debono

Electrome \& Cognition Modes in Plants: A Transdisciplinary Approach to the Eco-Sensitiveness of the World

Table 3: (continued).

- Associative learning \& decision-making: Recent researches of Gagliano (2016) demonstrated that plants are able of associative learning and anticipation (Pavlovian learning). If confirmed, these results could open a new measure of the cognitive capabilities of plants.

- Information processing: Following the Plant Neurobiology conferences (20052010), a lot of publications from Brenner, Trevawas, Mancuso, Balúska, Calvo, Keijzer, Souza, Gagliano, etc...were published about signalization and plant behavior (see Plant Behavior and Intelligence, Trewavas 2014). The idea of plant intelligence, cognition or consciousness is a source of debate (Alpi letter, see Taiz et al., 2019) and new discoveries show that if plants do not have neurons, they are able to feel, learn, memorize and communicate.

- Primary Meaning-Making (PM) / Bio-semiotics: It corresponds to a post-darwinian semiotic biology derived from the work of Jacob von Uexküll on animal ethology. Primary-meaning mechanisms create an Umwelt or a phenomenal world in which animals, but also other species like eukaryotes, unicellular organisms are actors. Plant-environment relationships have been little studied by Uexküll and are the object of our approach of plant mesology presented in Table 2. At the semiotic level, the concept of functional circle is assumed to be here a key component of agency and linked to subjective time and semiosis (Kalevi Kull, 2000). These bio-semiotic components have points in common with the work of Berque $(2014,2016)$ and the above-mentioned mesologists without having the same perspective.

- Mesological plasticity (MP): As presented in tables 1-2, following the Berquian presentation of the mesological relation, we have extended the description of the dynamic coupling to plants that are electromic ecoplastic interfaces and medial structures (Debono \& Souza 2019) presenting a high sensitiveness to their singular habitat, active perceptions and a trajective access to experience and/or cognition.

* Sources of some definitions: Wikipedia [WP] \& Stanford Encyclopedia of Philosophy [SEP]

\subsection{Learning and Complex Behaviors}

As we have shown, the best expression of these cognitive skills and of the richness and complexity of the plant life (or of tree interactions in the forest) can be obtained by continuous in situ electrophytographic (EPG) recordings in natural conditions (rather than in laboratories). They lead to the observation of complex emerging behaviors, according to the establishment of exhaustive criteria such as those previously described or still recently shown by Michmizos \& Hilioti (2018) about learning capacities and plant memory [85]. These authors discuss in particular the presence or not of internal representations of the outside world and of encoding in the form of engrams that may involve actin networks and feedback of the information learned, qualified as intelligent, but who are undoubtedly endowed with sensitivity and a cognitive aptitude which does not call upon any intentionality or subjectivity. According to these authors, this type of observation does not only concern epigenetic plasticity, but could be linked to the identification of unlisted mnemonic systems, for lack of adopting the right angle of view, such as the stabilization of the coactivation of patterns recruiting certain groups of cells, remodeling of the cytoskeleton, the emission of feedbacks \pm or molecular signals (like calcium waves) in plants. Another crucial demonstration in the advancement of our understanding in the field of plant learning is also linked to Gagliano's associative and non associative learning experiments, using either two groups of pea plants responding to differential conditioned responses or repeated shocks in Mimosa pudica's [86a, 86b].

Following the cognitive perspective of access to experience without representation of plants which are expressed, as for mammals, in terms of sensitiveness (and not only sensitivity, mainly sustained by signalisation and electrical networks), communication, memory or learning, we need to explore in deep the non-linear dynamic relationships between perception and integration. However, it is not so much their neural - or more precisely protoneural - ability that is the fruit of a common evolutionary process which has diverged, which is to be taken into account, but the moment when the dynamic coupling 'plant-milieu' and the cognitive apparatus as an emerging vector of this complex self-organized system become operational [6]. 
It involves, as in animals or humans, not only forms of phenotypic, onto- and epigenetic plasticity - essential for the survival of species and optimal organismic growth - but: 1/ an activation of perception-action loops linked to the plant-singular environment pair (plants are neither immobile, nor identical, nor passive) and $2 /$ an access to experience via a system of affordance (Gibson, 1966, 1977) $[69,87]$ or of mesological plasticity $[11,16]$.

We have already described the mesological link. The Gibson's term 'affordances' [87] describing the relationships between animals and the environment eliminates the mechanistic view of a "machine" animal and neutral environment. On the contrary it is active, in other words, the field of multiple possibilities of action that the animal chooses is easily transposed to plants in its sense of 'awakening sensitivity' to the surrounding world and processing information in interaction with the environment. This active plasticity has the potential to engender, in the first as in the other case and with different degrees of integration, a schema of interpretation of the outside world. This concept of opportunistic action in a bio- or even phytosemiotic environment (Kull, 2000) [88] and/or making action possible without causing it, is also totally transposable to plants following Calvo et al. (2011, 2017), provided that it do not limit it to direct perception and interaction with an environment considered unambiguous [40, 45]. Indeed, while vegetative semiotics is mainly aimed at morphogenesis and differentiation following the founding works of Uexküll taking into account the thresholds between species, the fact that it is subject to a changing environment and by ambiguous essence asks it to make 'choices' or at least to adopt complex dynamic behaviors where the conditions of survival, reactivity and growth are intimately linked to their interaction with the environment $[26,31]$.

\section{Third Included, Subjectity and Coextensive Reality}

The operative significance of biological cognition has been described further. Mesological theory, for its part, differentiates the subjectivity of the animal or man from the subjectity [50] of the subject included in an environment, which applies perfectly to plants. In fact, the observation of both autonomy and a mutual dependence between the living subject and his environment leads to the development of a perception-action loop, which is not neutral, but indicates, if not a "self", a presence to" others ", here determined by the environment. In other words, we need to take into consideration, not the objectification but subjectivity of the relation (at the biological scale), that is to say a reciprocal interdependence or subjection between the micro- and the macrocosm (cell vs organism) or the individual and the collective (organism vs society). The homeostasis of the living is preponderant and is always in a state of 'stable imbalance', therefore of interaction between the interior and exterior environment (as in transmembrane exchanges) or the passage from object to subject, but when there is proactive perception or attempt of knowledge of the other, this interpenetration of environments leads either to a dual state, object and subject at the same time, or to a ternary state (Table 1). This is the third point I would like to address, stemming both from mesological reflection (Uexkull, Berque) [27] and transdisciplinary studies (since the quantum revolution: Lupasco, Nicolescu) [89-92]. Here, the highlight of the notion of 'third included' which indicates since Antiquity (Plato, Proclus, Aristotle) and in several traditions (notably Far Eastern) with differences in interpretation around whether the Aristotelian terms A and non-A admit or not the inclusion of a third term and its meaning (the Chôra of Plato, the T state of Lupasco, the Indian Tetralemma).

If we put it back in our questioning with regard to the behavior of plants, it indicates in an illuminating way, not only the ternary subject-environment-world link and the formation of plastic complexes following the perceptual bonding operated by plants [23, 25], but also a 'Metaxu' (or an intermediary in reference to Plato) between the intelligible and the sensible [100]. This third term would support the otherness specific to the plant world (described, among other philosophical assertions as 'plant thinking' by Marder (2013) [93], in the sense that it derives from a subjectivity in animals or humans and from a subjectivity on the scale of plants, since there is internalization of the form that defines it. Now, it is precisely the definition of the concept of Plasticity (Debono, 1996, 2007) [22, 23] which first links form and matter before showing that this active binding (here perceptual and linked to evolutive processes: Debono 2004) [94] becomes 
Marc-Williams Debono

Electrome \& Cognition Modes in Plants: A Transdisciplinary Approach to the Eco-Sensitiveness of the World

irreversible when it forms plasticity complexes (CP) where plasticity is the included third [95].

We find an expression of it in the proprioceptive capacities of plants which clearly stand out from their phenotypic or epigenetic plasticity, in the sense that they call upon sensors of balance, gravity and positioning (verticality), but especially to a perception of their shape and of the deformation of their body, or even those of their congeners - like the canopy whose constrained plasticity optimizes the performance whatever the species (cooperative behavior which does not exclude competitiveness, moreover) - (Sack et al. 2006) [96]. These behaviors are widely described at the level of tree tops in the forest and of the deformation of trees subjected to intense stress such as strong wind (taking into account their sharing of light or their positioning and the presence of juveniles), which indicates an internalization or spatiotemporal elements of a decentralized representation, a perception of their presence in the world, even if it is not integrated in the cerebral sense of the term, and a capacity for association leading not only to reactions but to actions, and even feedback.

Are we not here describing a phenomenon of cognitive nature, whether it is located, distributed, embodied or extended as the interconnections in shared underground networks might suggest (Parise et al., 2019) [70]. Are we not here describing somatotopic phenomena at the scale of the entire plant, therefore delocalized and integrative but not involving any central unit? Phenomena using protoneural systems that transmit information at a distance, are able to control growth patterns in the case of circumnutation or responses encoding predictions of errors in perceptual learning processes? If we follow our reasoning, there is indeed no need to appeal to a brain and even less to a consciousness in plants (without need also to use the circular argument "no brain-no consciousness" recently argued by Taiz et al. 2019 [97], insofar as their hypersensitiveness to the environment and the cognitive capacities which result from it operate through nonlinear dynamic processes [6] spilling out across the entire plant body [6]. Perceptual and reactive processes requiring no supervision, which could explain, in the case of the physarum (but not in that of insects or birds with small brains), dazzling successes in the labyrinth test (root going to seek nitrogenous food in the case of plants) and a form of dispersed and non-localized cognition.

In this paper, we have given some empirical evidence, even we can discuss if empiricism is empirically false as Milkowski did it interestingly [63], several avenues that allow us to outline answers on access to experience and the cognitive nature of plants, understood as subjects capable of modifying their biodynamism and their behaviors, depending on the stimuli. It is now a question of moving forward on these avenues and in particular on the role of the electrome of plants, which a recent publication has shown, as was previously the case for osmotic stress [9], that an infection by pathogens affected the dynamics of the electrome, and that these alterations, which could be located far from the site of the infection (therefore involving the propagation of long-distance signals during plant-pathogen interactions), were detectable by EPG before the visible effects of infection on tomato plants (Simmi et al, 2020) [98]. This study recalls the interest of EPGs as early markers of activity and in situ diagnostic tools, but above all indicates the active role of this electrogenesis in the sensory sphere of the whole plant.

This pragmatic functional approach seems to us more able to scientifically advance the debate on plant intelligence, on condition of not compartmentalizing the plant-environment-world relationship, which according to our mesological approach, differentiates the singular environment or the Umvelt in which the plant evolves from the raw data of the environment to which it is subjected. As Tassin (2020) recently said: "The sensible is coextensive with the living as the environment is coextensive with the subject" [36]. It exists before perception and installs the presence of beings in the world. It is therefore a question of understanding how this dynamic coupling operates and what are the conditions for a mediation of the sensitiveness on the plant scale? For this, we have to think outside the box and consider the ternary plant-environment-world links and the perception-action loop as inherent in a form of knowledge of this world. 


\section{Conclusive Remarks: Rehabilitate the Ecosensitiveness of the World: A Transdisciplinary Challenge}

To conclude, plants considered to be primordial biosensors on the evolutionary scale of the living and the ecosystems governing us, have acquired the status of sensible subjects, which is a considerable step forward in integrative biology and in our own perception of the plant world. Our position based on recent developments in cell signaling and on the consideration of the electrome as a major support for plant information processing is that we can not be satisfied with these assertions and that we support the hypothesis of a progressive establishment of proactive perception systems during evolution leading to eco-sensitive and cognitive behaviors. It therefore seems high time to reassess the frontiers of cognition in plants without taboos or over-reference to the neuronal or intelligent model.

Scientifically, we propose to do this through the implementation of in situ integrated electrophytographic models such as those we have described, i.e. permanent spontaneous EPG activities subject to self-organized criticality (SOC) showing different patterns and colored noises depending on the type of stimuli or pathologies to which plants are subject as well as temporal correlations on large scales. EPGs are highly relevant early markers of activity that can be monitored by EPG kits in their natural environment permitting a lot of TD studies (concerning health, agriculture, biology, plasticity, communication...). More generally, plants must then be definitively considered as complex biodynamic systems embedded in an ever-changing milieu (an ecoplastic and mesological interface) and their study field need a redefinition of the sensory sphere, of subjectivity and of otherness, in other words, of its proper agentivity, ethology and intercognition (potentially including self recognition and internalization) with insects, plants, humans etc. This should lead us to a better understanding of the specific vegetal behavior as a whole, its own ontology and at what level of autonomy we accept to grade it among all other species (including unicellular organisms).

"Are plants cognitive?" ask recently Segundo-Ortin and Calvo (2019) responding to a critical review of Adams [99]. Clearly yes, if we assume firstly that it is a non-metaphorical argument, and secondly that plants, as all living systems, are cognitive agents, as admitted by the post-cognitivist current joining enactive to eco-responsible considerations. It is therefore a question of putting into perspective the cognitive value of the access to experience of plants understood as biological embodied cognitive systems allowing them, not only to exploit their surrounding environment (which give them great benefits), but also to show active perception and reaction to it. This behavior that can be proactive-anticipating modifications of its environment -, that memorize and learn, could be assimilated to a biosemiotic process of knowledge of the environment facilitated by the electrome and the hypersensitiveness of plants in their singular milieu. It defines for us a dynamic couple showing medial ability and a trajective way of expression (mesological plasticity) [11] or more literary, an "anchored intelligence" (Debono, 2020) [16].

We define then plants as electromic plastic interfaces implying endogenous and exogenous control of information, perception-action loops and high communicative skills, i.e. cognitive entities, but not as 'neuronal plants' or structures containing phytoneurones, as previously described concerning their bioelectrical transmission [11]. Indeed, this causes semantic disorders or confusions which do not seem to me to bring crucial elements (we know that plants do not have a brain or neurons), or then we must speak of protoneural dynamics and place ourselves on the level of convergences or divergences of species during evolution [94], where the notions of plant sensitiveness and biological cognition support the comparison with the animal kingdom and indicate differentiated modes of cognition (Table 3).

Indeed, beyond the recognition of the sensitivity, the cognition or even the awareness of plants, it is the entire domain of the sensitiveness and of the nature-culture relationships that must be re-examined. This concerns directly the interspecific links, the evolutionary scales and the re-evaluation of value systems and/or notions seemingly acquired about cognition, intelligence, sensitiveness vs sensitivity or even socioanthropological considerations. Debate which, on the scale of questioning "the intelligence of plants" [31] cannot be approached unilaterally by botanists, biologists, anthropologists or philosophers, but only by the opening of a cross-pollination and a field of transdisciplinary studies on this vast question [25]. We situate it precisely through a careful examination of interactive ecosystems, perceptual and cognitive modes of 
Marc-Williams Debono

Electrome \& Cognition Modes in Plants: A Transdisciplinary Approach to the Eco-Sensitiveness

of the World

apprehension of the ecosensitiveness of the world (Debono, 2021) [82]. And among these TD approaches, we can consider that the singularity and otherness of the complex biodynamic units that plants represent are flouted by a socioeconomic system (the 'Capitalocene' described by Marder and Haraway) [93, 101] centered on the anthropocentric prerogatives of man which could have serious consequences on the planetary balance and the place of man in the future.

To conclude, confluent empirical, epistemological or scientifically demonstrated arguments (see Garzón, Calvo, Segundo-Ortin, Milkowski, Marder, Debono, Keijzer, Baluska, Gagliano, Souza etc.) show that plants, as most of living organisms, have clear cognitive abilities, whatever they are classified. The transdisciplinary challenge to which we must respond, as previously described by Debono [34, 95], a coreTD biosemiotic research area reevaluating the frontiers in cognitive sciences including phenomenological and mesological approaches of sensory and biodynamic complexes [20]. Only this crossed field open to the universal but also to diversified messages of complex non-linear dynamic systems, trans-subjectivity and the third included [92] could ultimately lead to a redefinition of decultured or too anthropized attributes and clarify the debate on the modes of cognition or learning of plants, fungi, protists and more generally of all living subjects. Our own human status, today more acutely perceptible in its fragility (Covid 19) depends on it, not to mention the global threats linked to the consequences of both the era of Anthropocene and the Capitalocene. It is therefore urgent to rediscover the frontiers of cognition and of the sensible world, taking into account the phylogenetic origins of biological cognition and of elementary learning processes (Van Duijn, 2017) [102] as well as their ontological significance.

Funding: This research received no external funding.

Conflicts of Interest: The author declares no conflict of interest.

\section{References}

[1] De Loof, A. (2016). The cell's self-generated "electrome": The biophysical essence of the immaterial dimension of Life? Communicative 8 Integrative Biology, 9/5, e1197446.

[2] de Toledo, G.R.A, Parise, A.G., Simmi, F.Z., Costa, A.V.L., Senko L.G.S., Debono M.W., Souza G.M. (2019). Plant electrome: the electrical dimension of plant life. Theor. Exp. Plant Physiol., 31, 21-46. DOI : https://doi.org/10.1007/s40626-019-00145-x

[3] Hedrich, R., Salvador-Recatala, V., Dreyer, I. (2016). Electrical wiring and long-distance plant communication. Trends in Plant Science, 21(5), 376-387.

[4] Choi, W.G., Miller, G., Wallace, I. et al (2017) Orchestrating rapid long-distance in plants with Ca2+, ROS and electrical signals. The Plant Journal, 90, 698-707. DOI : https://doi.org/10.1111/tpj.13492

[5] Debono, M.W. and Bouteau, F. (1992). Spontaneous and evoked surface potentials in Kalanchoë tissues. Plant Physiology (Life Sciences Advances), 11, 107-117.

[6] Debono, M.W. (2013). Dynamic protoneural networks in plants. A new approach of extracellular spontaneous potential variations. Plant Signaling \& Behavior, 8(6), 1-6. DOI: https://dx.doi.org/10.4161\%2Fpsb.24207

[7] Masi, E., Ciszak, M., Stefano, G., L. Rena, L., Azzarello, E., Pandolfi, C., S. Mugnai, F., Balūska, F., Arecchi, F.T. and Mancuso, S. (2009). Spatiotemporal dynamics of the electrical network activity in the root apex. PNAS (Proc Natl Acad Sci) USA, 106, 4048-4053.

[8] Cabral, E.F., Pecora, P.C., Arce, A.I.C., Tech, A.R.B., Costa, E.J.X. (2011). The oscillatory bioelectrical signal from plants explained by a simulated electrical model and tested using Lempel-Ziv complexity. Computers 86 Electronics in Agriculture, 76, 1-5.

[9] Saraiva, G.R.F., Ferreira, A.S., Souza, G.M. (2017). Osmotic stress decreases complexity underlying the electrophysiological dynamic in soybean. Plant Biol. (Stuttg.), 19(5), 702-708. DOI: https://doi.org/10.1111/plb.12576

[10] Souza, G.M., Ferreira, A.S., Saraiva, G.F.R., Toledo, G.R.A. (2017). Plant "electrome" can be pushed toward a self-organized critical state by external cues: evidences from a study with soybean seedlings subject to different environmental conditions. Plant Signal. Behav. 12, e1290040. DOI: https://doi.org/10.1080/15592324. 2017.1290040 
[11] Debono, M.W. \& Souza, G.M. (2019). Plants as electromic plastic interfaces: A mesological approach. Progress in Biophysics and Molecular Biology, 146, 123-133. DOI : https://doi.org/10.1016/j.pbiomolbio.2019.02.007

[12] Froom, J. and Lautner, S. (2007). Electrical signals and their physiological significance in plants. Plant, Cell 86 Environment, 30: 249-57.

[13] Pereira, D.R., Papa, J.P., Saraiva, G.F.R., Souza, G.M. (2018). Automatic classification of plant electrophysiological responses to environmental stimuli using machine learning and interval arithmetic. Computers and Electronics in Agriculture, 145: 35-42.

[14] Tran, D., Dutoit, F., Najddenovska, E., Wallbridge N., Plummer C., Mazza M., Raileanu, L.E. \& Camps, C. (2019). Electrophysiological assessment of plant status outside a Faraday cage using supervised machine learning. Scientific reports Nature Research, 9, 17073. DOI: https://doi.org/10.1038/s41598-019-53675-4

[15] Mousavi, S.A.R., Nguyen, C.T., Farmer, E.E., Kellenberger, S. (2014). Measuring surface potential changes on leaves. Nat Protocol, 9(8), 1997-2004.

[16] Debono, M.W. (2020). L'électrome des plantes: une intelligence ancrée dans un corps, un milieu et un monde in L'intelligence des plantes en question, Hermann, Paris.

[17] Debono, M.W. (2018). Flux d'information sensoriels et stratégies de communication intelligentes chez les plantes in La mésologie, un autre paradigme pour l'anthropocène? M. Augendre, J.P. Llored \& Y. Nussaume Dir(s), Hermann, Paris, 311-324.

[18] Berque, A. (2014). Formes empreintes, formes matrices, Asie orientale, Franciscopolis.

[19] Berque, A. (2014). La mésologie, pourquoi et pour quoi faire? Presses Univ. de Paris-Ouest.

[20] Berque, A. (2008). Écoumèène. Introduction à l'étude des milieux humains, Paris, Belin.

[21] Debono, M.W. (2016). Perception et plasticité active du monde. Séminaire EHESS, Paris. Published in Mesologiques, https://ecoumene.blogspot.com/2016/03/perception-et-plasticite-m-w-debono.html (accessed November 16, 2020).

[22] Debono, M.W. (1996).L'ère des plasticiens, Aubin Ed.

[23] Debono, M.W. (2007). Le concept épistéémologique de plasticié. Dogma, Rev. of Philos. E Human Sci. http://www.dogma.lu/txt/MWD-ConceptPlasticite.htm (Accessed November 16, 2020).

[24] Debono, M.W. (2010). Le complexe de plasticité, état des lieux et immersion, Plastir 18, 1-23 http://plasticitessciences-arts.org/PLASTIR/Debono\%20P18.pdf (Accessed November 17, 2020).

[25] Debono, M.W. (2012). Etats des lieux de la plasticité. 1: Les interfaces plastiques \& 2: La Plasticité de l'esprit, http://www.implications-philosophiques.org/langage-et-esthetique/implications-esthetiques/etatdes-lieux-de-la-plasticite/; http://www.implications-philosophiques.org/langage-et-esthetique/implicationsesthetiques/la-plasticite-de-lesprit/), Implications Philosophiques, (Accessed November 17, 2020).

[26] Berque, A. (2016). Plasticité mésologique? Philo/ENP Blog (August) https://www.editionsdenullepart.info/index.php/ci3/210-augustin-berque/2529-plasticite-mesologique (Accessed November 16, 2020).

[27] Berque, A. (2017). Trajection et réalité. Presented at the Colloque de Cerisy, La mesologie, un autre paradigm pour l'anthropocène?, Cerisy La Salle, France, August 30-September 6. http://www.cciccerisy.asso.fr/mesologie17.html

[28] Olkowicz, S., Kocourek, M., Lučan, R.K., Porteš, M., Fitch, T.W., Herculano-Houzel, S. and Němec, P. (2016). Birds have primate-like numbers of neurons in the forebrain. PNAS 113 (26), 7255-7260. DOI: https://doi.org/10.1073/pnas.1517131113

[29] Fichtel, C., Dinter K., Kappeler P.M. (2020). The lemur baseline: how lemurs compare to monkeys and apes in the Primate Cognition Test Battery 8, e10025. DOI: 10.7717/peerj.10025

[30] Hug, I., Deshpande, S., Sprecher, K.S., Pfohl, T., Urs, Jenal U. (2017). Second messenger-mediated tactile response by a bacterial rotary motor. Science 358(6362), 531-534. DOI: 10.1126/science.aan5353

[31] Debono, M.W. (2020). L'intelligence des plantes en question, Hermann, Paris.

[32] Debono, M.W. (2020): The dataflow paradigm, dataïsm and the myth of singularity in Big Data and singularities, https://humanitiesartsandsociety.org/magazine/the-dataflow-paradigm-dataism-and-the-mythof-singularity/ (accessed November 17, 2020), HAS Magazine 01, 88-95, UNESCO-MOST, Paris. 
Marc-Williams Debono

Electrome \& Cognition Modes in Plants: A Transdisciplinary Approach to the Eco-Sensitiveness of the World

[33] Mancuso, S. and Viola, A. (2015). Brillant Green, Washington, Island Press.

[34] Debono, M.W. (2013). Perceptive levels in plants: a transdisciplinary challenge in living organism's plasticity, Transdisciplinary Journal of Engineering \& Science, 4, 21-39. DOI: https://doi.org/10.22545/2013/00044

[35] Benasayag, Miguel (2017). La singularité du vivant. Le Pommier, Paris.

[36] Tassin, J. (2020). Pour une écologie du sensible. Odile Jacob, Paris.

37(a) Brenner, E.D., Stahlberg, R., Mancuso S., Vivanco, J., Baluska, F. and Van Volkenburgh, E. (2006). Plant neurobiology: an integrated view of plant signaling. Trends in Plant Sciences, 11/8, 414-419.

[37] (b) Baluska, F., Mancuso, S., Volkmann, D., (2006). Communication in Plants: Neuronal aspects of plant life, Springer Verlag.

[38] Robert, H.S., Park, C., Gutièrrez, C.L., Wójcikowska, B., Pěnčík, A., Novák, O., Chen, J., Grunewald, W., Dresselhaus, T., Friml, J., Laux, T. (2018). Maternal auxin supply contributes to early embryo patterning in Arabidopsis. Nature Plants. DOI: 10.1038/s41477-018-0204-z

[39] Msimang, P. (2016). I, Plant. Sterelny's thought in a hostile world and plant cognition. University of KwazuluNatal. DOI: $10.13140 / R G \cdot 2.2 .30862 .15687$

[40] Calvo, P., Sahi, V.P., Trewavas, A., 2017. Are plants sentient? lant Cell Environ. 40, 2858e2869. DOI: https://doi.org/10.1111/pce.13065

[41] Noë, A. (2004). Action in perception. Cambridge, The MIT Press. ISBN 978-0-262-14088-1

[42] Churchland, P.S. and Sejnowski, T.J. (1992). The Computational Brain. Cambridge, Massachusetts: The MIT Press.

[43] Varela, F., Thomson, E., Rosch, E. (1991). The embodied mind: Cognitive science and human experience, The MIT Press, Cambridge, MA, USA.

[44] Stewart J., Gapenne O. \& Di paolo E.A. Eds. (2010). Enaction: Toward a New Paradigm for Cognitive Science. The MIT Press, USA.

[45] Calvo, P. \& Keijzer, F. A. (2011). Plants: Adaptive behavior, root-brains, and minimal cognition. Adaptive Behavior, 19, 155-171.

[46] Trewavas, A. (2003). Aspects of plant intelligence. Annals of Botany, 92, 1-20.

[47] Trewavas, A. and Balūska, F. (2011). The ubiquity of consciousness, cognition and intelligence in life. EMBO Reports 12(12), 1221-1225. DOI: 10.1038/embor.2011.218

[48] Maturana, H. and Varela, F. (1980). Autopoiesis and Cognition: The realization of the living. D. Reidel, Ed.

[49] Varela, F. (1979). Principles of Biological Autonomy. New York: Elsevier Science Pub.

[50] Berque, A. (2019). De Merleau Ponty en mésologie, https://ecoumene.blogspot.com/2019/09/de-merleauponty-en-mesologie-augustin.html (accessed November 17, 2020).

[51] Lev-Yadun, S. (2013). The enigmatic fast leaflet rotation in Desmodium motorium. Butterfly mimicry for defense? Plant Signal Behavior 8, e24473.

[52] Gagliano, M., Vyazovskiy, V., Grimonprez, M.\& Depczynski, M. (2016). Learning by association in plants, Nature.com, Scientific Reports, 6, 1-9. DOI: 10.1038/srep38427

[53] Moulia, B. and Fournier, M. (2009). The power and control of gravitropic movements in plants: a biomechanical and systems biology view, Journal of Experimental Botany, 60(2), 461-486.

[54] Hamant, O. and Moulia, B. (2016). How do plants read their own shaps ? New phytologist, 212, 333-337.

[55] Sterelny, K. (2003). Thought in a Hostile World: the Evolution of Human Cognition. Blackwell Publishing Ltd, Oxford, UK.

[56] Simard, S.W., Beiler, K.J., Bingham, M.A., Deslippe, J.R., Philip, L.J., Teste, F.P. (2012). Mycorrhizal networks: mechanisms, ecology and modeling. Fungal Biol. Rev., DOI: 26, 39e60

[57] Stock, W.D., Byrne, M., Pavarani, E., Fogu, L., Clemente, N., van Etten, E.J., Delnevo, N. (2020). Pollen adaptation to ant pollination: a case study from the Proteaceae. Annals of Botany. DOI: 10.1093/aob/mcaa058 
[58] Margulis, L. (2009). Symbiogenesis, Com. at the colloquium "Tribute to Darwin. A debate on evolution". Balliol College, May 8, Oxford.

[59] Margulis, L. and Dorion, S. (2003). Acquiring genomes: a theory of the origins of species. Basic, New York.

[60] Thoroggod, J.C. \& Santos, C. (2020). Langsdorffia: Creatures from the deep? Plants, People, Planet, 2, 181-185. DOI: https://doi.org/10.1002/ppp3.10102

[61] Garzon, F.C. (2007). The quest for cognition in plant neurobiology. Plant Signal Behav., 24, $208-211$.

[62] Keijzer, F. Duijn, M.V., Lyon, P. (2017). What nervous systems do: early evolution, input-output, and the skin brain thesis. Adaptative behavior, 21(2), 67-85. DOI: 10.1177/1059712312465330

[63] Milkowski, M. (2017). Is empiricism empirically false? Lessons from early nervous systems. Biosemiotics, 10 (2), 229-245.

[64] Keijzer, F. (2015). Moving and sensing without input and output: early nervous systems and the origins of the animal sensorimotor organization. Biology and philosophy, 30, 311-331.

[65] Wiljes, O.O.D., Elburg, R.V., Biehl, M., Keijzer, F. (2015). Modeling spontaneous activity across an excitable epithelium: Support for a coordination scenario of early neural evolution. Front. Comput. Neurosci., 9, 110. DOI: 10.3389/fncom.2015.00110

[66] Parker, G. H. (1919). The elementary nervous system. Philadelphia, PA.

[67] Mackie, G. (1990). The Elementary Nervous System Revisited. American Zoologist, 30(4), 907-920. DOI:10.1093/ICB/30.4.907

[68] Arendt, D., Tosches, M. A., \& Marlow, H. (2015). From nerve net to nerve ring, nerve cord and brain. Evolution of the nervous system. Nature Reviews Neuroscience 17(1), 61-72. DOI: 10.1038/nrn.2015.15

[69] Gibson, J. J. (1966). The senses considered as perceptual systems. Boston: Houghton-Mifflin.

[70] Parise, A., Gagliano, M. \& Souza, G.M. (2020). Extended cognition in plants : is it possible ?Plant signaling \& behavior, 15(2): 1710661. DOI: 10.1080/15592324.2019.1710661

[71] Vogel, D. and Dussutour, A. (2016). Direct transfer of learned behaviour via cell fusion in non-neural organisms.PNAS B, 283/1845. DOI: 10.1098/rspb.2016.2382

[72] Nakagaki, T., Yamada, H. and Tóth, A. (2000). Intelligence: Maze-solving by an amoeboid organism. Nature, 407, 6803: 470. DOI: 10.1038/35035159

[73] Tero, A., Takagi, S., Saigusa, T., Ito, K., Bebber, Dan P., Fricker, M.D., Yumiki, K., Kobayashi, R. and Nakagaki, T. (2010). Rules for biologically inspired adaptive network design. Science, 327/5964, 439-442.

[74] Saigusa, T., Tero, A., Nakagaki, T. and Kuramoto, Y. (2008). Amoebae anticipate periodic events. Physical Review Letters, 100, 018101. DOI: https://doi.org/10.1103/PhysRevLett.100.018101

[75] Schaaps, P., Barrantes, I., Minx, P., Sasaki, N., Anderson, R.W., Bénard, M., Biggar, K.K., Buchler, N.E., Bundschuh, R., Chen, X. et al. (2015). The Physarum polycephalum genome reveals extensive use of prokaryotic two-component and metazoan-type tyrosine kinase signaling. Genome Biology and Evolution, 8(1), $109-125$. DOI: https://doi.org/10.1093/gbe/evv237

[76] Broussard, A., Delescluse, J., Pérez-Escudero, and Dussutour, A. (2019). Memory inception and preservation in slime moulds : the quest for a common mechanism. Phil. Transactions of the Royal Society B., 374, 20180368. DOI: https://doi.org/10.1098/rstb.2018.0368

[77] Martin, L., Leblanc-Fournier, N., Julien, J.L., Moulia, B., Coutand, C. (2010). Acclimation kinetics of physiological and molecular responses of plants to multiple mechanical loadings. J. Exp. Bot. 61, 2403-12.

[78] Gagliano, M., Mancuso, S., Robert, D. (2012). Towards understanding plant bioacoustics. Trends in Plant Science, 17(6), 323-325.

[79] Mescher, M.C., Runyon, J.B., De Moraes, C.M. (2006). Plant host finding by parasitic plants: a new perspective on plant to plant communication. Plant Signaling \&S Behavior, 1, 284-6.

[80] Abramson, C.I. and Chicas-Mosier, A.M. (2016). Learning in Plants: Lessons from Mimosa pudica. Frontiers in Psychology, 7(122), 1-9. DOI: 10.3389/fpsyg.2016.00417

[81] Volkov, A.G. (2012). Plant Electrophysiology: Methods and Cell Electrophysiology. Springer, Berlin. DOI: https://doi.org/10.1007/978-3-642-29119-7 
Marc-Williams Debono

Electrome \& Cognition Modes in Plants: A Transdisciplinary Approach to the Eco-Sensitiveness

of the World

[82] Debono, M.W. (2021). Intelligence of plants: when science requestions the ecosensitiveness of the world, Third World Congress of Transdisciplinarity, Nov. 2-6, Mexico City. https://ciret.hypotheses.org/3world-congress-ontransdisciplinarity-iiicmt

[83] Morin, E. (1977-1986). La Méthode, Le Seuil, Coll. Le point, Paris, Tome 1-3.

[84] Berque, A. (2019). Does nature think? Introduction to the Colloquium: Does nature think evolution?

[85] Michmizos, D., Hilioti, Z. (2018). A roadmap towards a functional paradigm for learning \& memory in plants. Journal of plant physiology, 232, 209-215. DOI: https://doi.org/10.1016/j.-jplph.201811.002

86(a) BGagliano, M., Renton, M., Depczynski, M. Mancuso, S. (2014). Experience teaches plants to learn faster and forget slower in environments where it matters. Oecologia, 175(1), 63-72. DOI :10.1007/s00442-013-2873-7

[86] (b) Gagliano, M., Abramson, C.I. \& Depczynski, M. (2018). Plants learn and remember: lets get used to it. Oecologia, 186, 29-31. DOI : https://link.springer.com/article/10.1007/s00442-017-4029-7

[87] Gibson, J. J. (1977). The theory of affordances. In Shaw, R. \& Brandsford J. Eds. Perceiving, Acting, and Knowing. Toward an Ecological Psychology, 127-143.

[88] Kalevi, K. (2000). An introduction to phytosemiotics: semiotic botany and vegetative sign systems. Sign Systems Studies, 28: 326-350. http://www.zbi.ee/ kalevi/phyto.htm

[89] Lupasco, S. (1970). Les trois Matiéres. Julliard Ed. 10/18, Paris.

[90] Lupasco, S. (1989). L'expérience microphysique et la pensée humaine. Le Rocher, Paris.

[91] Nicolescu, B. (2002). Manifesto of Transdisciplinarity. State Univ. of New York (SUNY) Press, New York, translated from French by Karen-Claire Voss.

[92] Nicolescu, B. (2011). Methodology of transdisciplinarity, levels of reality, logic of the included middle and complexity. In Transdisciplinarity bridging natural science, social science, humanities and engineering, Ertas, A. Ed., Atlas Books, 22-45.

[93] Marder, M. (2013). Plant-Thinking - A Philosophy of Vegetal Life. Columbia University, Press.

[94] Debono, M.W. (2004). From perception to consciousness: an epistemic vision of evolutionary processes, Leonardo The MIT Press, 37(3), 243-248. DOI: https://doi.org/10.1162/0024094041139364

[95] Debono, M.W. (2008). Transdisciplinarity. A new approach to meta-dynamics and consciousness. In Transdisciplinarity. Theory and practice. Nicolescu, B, Ed., Hampton Press Creskill New jersey, USA.

[96] Sack, L., Melcher, P.J., Liu, W.H., Middleton, E. and Tyler, P. (2006). How strong is intracanopy leaf plasticity in temperate deciduous trees? American Journal of Botany, 93(6), 829-839.

[97] Taiz, L., Alkon, D., Draguhn, A., Murphy, A., Blatt, M., Hawes, C., Thiel, G. and Robinson, D.G. (2019). Plants Neither Possess nor Require Consciousness, Trends in Plant Science, 24(8), 677-687. DOI : https://doi.org/10.1016/j.tplants.2019.05.008

[98] Simmi, F.Z., Dallagnol, L.J., Ferreira, A.S., Pereira, D.R., Souza, G.M. (2020). Electrome alterations in a plant-pathogen system: toward early diagnosis. Bioelectrochemistry, 133, 107403. DOI : https://doi.org/10.1016/j.bioelechem.2020.107493

[99] Segundo-Ortin, M. \& Calvo, P. (2019) Are plants cognitive? Studies in History and Philosophy of Science Part A., 73, 1-76.

[100] Debono, M.W. (2021). From the intelligible to the sensible - Crossed perspectives in the 21st century. Book in press.

[101] Haraway, D. (2014). Anthropocene, Capitalocene, Chthulucene: Staying with the Trouble presented by D. Haraway in Anthropocene: Arts of Living on a Damaged Planet, on 05/09/2014.

[102] Van Diujn, M. (2017). Phylogenetic origins of biological cognition: convergent patterns in the early evolution of learning. Interface focus: a theme supplement of Journal of the Royal Society interface 7(3), 20160158. The Royal Society Publishing. 


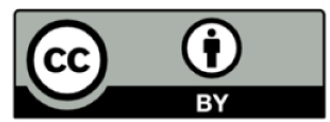

Copyright (C)2019 by the author. This is an open access article distributed under the Creative Commons Attribution License (https://creativecommons.org/licenses/by/4.0/), which permits unrestricted use, distribution, and reproduction in any medium, provided the original work is properly cited.

\section{About the Author}

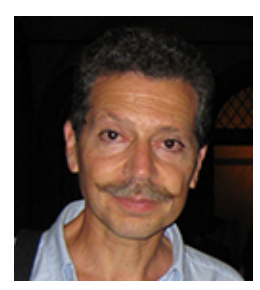

Marc-Williams Debono is a French neurobiologist currently in charge of an Art \& Science pole in the south of Paris (CC91, Paris Saclay). Apart from his work in neuroscience, particularly related to the study of neurodegenerative diseases, he more generally explores the plasticity of living systems and in particular that of the plant world (bioelectricity and modes of perception). Member of the International Center for Transdisciplinary Research and Studies (CIRET), he is also president-founder of the transdisciplinary Plasticities Sciences Arts (PSA) research group (2000) that aims at developing the concept of plasticity and opening new crossroads between sciences, arts and humanities. Since 2005, he publishes in open source on the PSA website the Transdisciplinary Review of Human Plasticity PLASTIR in which the various attributes of plasticity are explored by transdisciplinary researchers. Among his books or chapter of books: The Era of Plasticians, Aubin Ed. (1996); The Plastic Code of Life in 'Transdisciplinarity', Acts of the 1st Int. Congress of transdisciplinarity, Hugin Ed., (1999). A transdisciplinary approach towards consciousness in 'Transdisciplinarity - Theory and Practice', B. Nicolescu Ed, Hampton Press, Cresskill, NJ 2008; The plasticity of Memories: Convergences between archetypes and complex of plasticity, Acts of the Int. Conf. 'Jung and the Sciences', Free University of Brussels, Szafran, Baum \& Decharneux EME Ed., 2009. Scientific Research, Plasticity and Transdisciplinarity with M. Thieriot, P. Loisel, P. Ghills \& U. D'Ambrosio in 'The community of practices as a tool of interreligious and intercultural dialogue' S. Guetta \& A. Verdiani Eds., Firenze Univ. Press, 2011; The Archipelic fruits in 'Glissant-World', L'Harmattan Ed., 2012. Writing and plasticity of thought, Anima Viva Ed., 2015; Sensory flows of information and intelligent communication in plants in 'Mesology, another paradigm for the Anthropocene?', J.P. Llored, M. Augendre, Y. Nussaume Eds., Hermann 2018. Questioning plant intelligence, Hermann Ed., 2020. More complete information is available in dedicated sections of the PSA Website (http://www.plasticites-sciences-arts.org/). 